OPEN ACCESS

Edited by:

Jee Hyun Kim,

Florey Institute of Neuroscience and

Mental Health, Australia

Reviewed by:

Kenii Hashimoto,

Chiba University, Japan

Caitlin Cowan,

University College Cork, Ireland

*Correspondence:

Ying Guo

guoying1@mail.kib.ac.cn

Huai-Rong Luo

luohuairong@mail.kib.ac.cn

Received: 04 February 2019

Accepted: 24 May 2019

Published: 18 June 2019

Citation:

Guo Y, Xie J-P, Deng K, Li X, Yuan Y, Xuan $Q$, Xie J, He X-M, Wang $Q$, Li J-J and Luo H-R

(2019) Prophylactic Effects of Bifidobacterium adolescentis on

Anxiety and Depression-Like Phenotypes After Chronic Stress:

A Role of the Gut

Microbiota-Inflammation Axis.

Front. Behav. Neurosci. 13:126. doi: 10.3389/fnbeh.2019.00126

\section{Prophylactic Effects of Bifidobacterium adolescentis on Anxiety and Depression-Like Phenotypes After Chronic Stress: A Role of the Gut Microbiota-Inflammation Axis}

\author{
Ying Guo 1,2,3,4*, Jian-Ping Xie ${ }^{5}$, Ke Deng ${ }^{1,4}$, Xia Li ${ }^{3}$, Yun Yuan ${ }^{3}$, Qun Xuan ${ }^{3}$, Jing Xie ${ }^{1}$, \\ Xiao-Ming He ${ }^{1}$, Qian Wang ${ }^{3}$, Juan-Juan $\mathrm{Li}^{3}$ and Huai-Rong Luo ${ }^{1,2,4 *}$ \\ 'State Key Laboratory of Phytochemistry and Plant Resources in West China, Yunnan Key Laboratory of Natural Medicinal \\ Chemistry, Kunming Institute of Botany, Chinese Academy of Sciences, Kunming, China, ${ }^{2}$ Key Laboratory for Aging and \\ Regenerative Medicine, Department of Pharmacology, School of Pharmacy, Southwest Medical University, Luzhou, China, \\ ${ }^{3}$ School of Basic Medical Sciences, Kunming Medical University, Kunming, China, ${ }^{4}$ University of Chinese Academy of \\ Sciences, Beijing, China, ${ }^{5}$ Library, Yunnan Minzu University, Kunming, China
}

Stress disturbs the balance of the gut microbiota and stimulates inflammationto-brain mechanisms. Moreover, stress leads to anxiety and depressive disorders. Bifidobacterium adolescentis displays distinct anti-inflammatory effects. However, no report has focused on the anxiolytic and antidepressant effects of $B$. adolescentis related to the gut microbiome and the inflammation on chronic restraint stress (CRS) in mice. We found that pretreatment with $B$. adolescentis increased the time spent in the center of the open field apparatus, increased the percentage of entries into the open arms of the elevated plus-maze (EPM) and the percentage of time spent in the open arms of the EPM, and decreased the immobility duration in the tail suspension test as well as the forced swimming test (FST). Moreover, B. adolescentis increased the sequence proportion of Lactobacillus and reduced the sequence proportion of Bacteroides in feces. Furthermore, B. adolescentis markedly reduced the protein expression of interleukin-1 $\beta$ (IL-1 $\beta)$, tumor necrosis factor $\alpha$ (TNF- $\alpha), p$-nuclear factorkappa B (NF-кB) p65 and Iba1 and elevated brain derived neurotrophic factor (BDNF) expression in the hippocampus. We conclude that the anxiolytic and antidepressant effects of $B$. adolescentis are related to reducing inflammatory cytokines and rebalancing the gut microbiota.

Keywords: Bifidobacterium adolescentis, antidepressant, chronic restraint stress, gut microbiota, inflammation

\section{INTRODUCTION}

With high mortality and morbidity, depression is a common and recurrent mood disorder accompanied by behavioral deficits (McKeever et al., 2017). Evidence shows that response to the first-line treatment of depression is $40 \%-60 \%$, while remission following antidepressant treatment is $30 \%-45 \%$ (Trivedi et al., 2006). Thus, our efforts have focused on developing better antidepressant drugs. 
In recent years, emerging evidence has suggested an involvement of the gut microbiota in inflammation, brain development and behavior (Evrensel and Ceylan, 2015). The relationship between microbiota and anxiety/depression has been studied by the chronic restraint stress (CRS) model, in which the gut microbiota, specifically the abundance of Allobaculum, Bifidobacterium, Turicibacter and Clostridium, is altered (Wong et al., 2016). It is becoming apparent that probiotics induce substantial impacts on the health of the host. The absence of probiotic bacteria in the gut is implicated in the etiology of depression (Desbonnet et al., 2008), and additionally, the prolonged intake of probiotics (Lactobacillus helveticus R0052 and Bifidobacterium longum R0175) has favorable effects on anxiety- and depression-related behaviors without the presence of any adverse events (Messaoudi et al., 2011). Studies have found that Bifidobacterium has positive effects on stress-related diseases (Meyer and Vassar, 2018), and furthermore, the probiotic Bifidobacterium infantis may possess antidepressant properties (Desbonnet et al., 2008). However, the exact mechanisms underlying the antidepressant effect of Bifidobacterium in connection with the brain-gut axis remain poorly understood.

Inflammatory mechanisms mediate increased stress responsiveness and depression susceptibility (Hennessy et al., 2019). The increased release of peripheral cytokines exacerbates anxiety- and depression-like behaviors in stressed animals (Hodes et al., 2014). In addition, interleukin (IL)$1 \beta$ is pivotal to the acquisition of depressive phenotypes in stressed animals (Maes et al., 2012). Antidepressant effects occur when the interleukin-1 $\beta$ (IL-1 $\beta$ ) level is decreased (Zhang et al., 2015). The data from a clinical study suggest that plasma tumor necrosis factor (TNF) $\alpha$ is also correlated with depression severity (Oglodek et al., 2017), and anti-TNF- $\alpha$ treatment alleviates depressive mood (Krishnan et al., 2007). In chronic stress models, microglial activation is significantly increased in the cingulate and medial orbital cortices, nucleus accumbens, caudate putamen, amygdala and hippocampus in the mouse brain (Farooq et al., 2012), and furthermore, the levels of IL-1 $\beta$, IL- 6 and tumor necrosis factor $\alpha$ (TNF- $\alpha$ ) are increased in the substantia nigra (de Pablos et al., 2014). Stress can disturb the balance of the gut microbiota, stimulate inflammation-to-brain mechanisms, and lead to microglia activation in depressive disorders (Maes, 2008). Nuclear factor $\kappa \mathrm{B}(\mathrm{NF}-\kappa \mathrm{B})$ is one of the major transcription factors that mediate inflammatory responses, and the activation of NF- $\mathrm{B}$ in HT-29 cells can be inhibited by pre-incubation with Bifidobacterium adolescentis NCC251 (Riedel et al., 2006). B. adolescentis IM38 can regulate the Proteobacteria to Bacteroidetes ratio in the gut microbiota and inhibit NF- $\kappa \mathrm{B}$ activation in the colon (Lim and Kim, 2017). B. adolescentis NK98 can suppress the occurrence and development of anxiety/depression, the infiltration of activated microglia into the hippocampus, and hippocampal NF- $\kappa$ B activation caused by acute immobilization stress (Jang et al., 2019). However, for CRS, the underlying connection between the anxiolytic and antidepressant effects of $B$. adolescentis, the gut microbiota, and inflammation are still unclear.
In this study, we investigated the anxiolytic and antidepressant effects of $B$. adolescentis related to the gut microbiota, inflammation, and behavior in CRS mice to evaluate the gut microbiota and inflammation as potential therapeutic targets in anxiety and depression.

\section{MATERIALS AND METHODS}

\section{Animals}

Male ICR mice (6 weeks old) were purchased from Kunming Medical University. The mice were housed in groups of 4-5 per cage $(290 \mathrm{~mm} \times 178 \mathrm{~mm} \times 150 \mathrm{~mm})$ in a room under normal conditions $\left(22 \pm 1^{\circ} \mathrm{C}, 50 \pm 2 \%\right.$ humidity, and a $12-\mathrm{h}$ light/12-h dark cycle) with free access to food and water. The animals were adapted to the laboratory conditions for 1 week before the experiment. The procedures were approved by the Institutional Animal Care and Use Committee of Kunming Medical University and were performed in accordance with the Guide for the Care and Use of Laboratory Animals.

\section{Experimental Design and Sample Collection}

\section{Experiment 1}

The mice were randomly divided into five groups: the Con group, which received $10 \mathrm{~mL} / \mathrm{kg}$ distilled water; the Ami group, which received $10 \mathrm{mg} / \mathrm{kg}$ amitriptyline (the dose was determined by our preliminary experiments and the references; Manning et al., 2014; Sanna et al., 2017); the Bif 0.25 (Bif) group, which received $0.25 \times 10^{9} \mathrm{CFU} / \mathrm{kg} B$. adolescentis; the Bif 0.5 group, which received $0.5 \times 10^{9} \mathrm{CFU} / \mathrm{kg} B$. adolescentis; and the Bif 1 group, which received $1 \times 10^{9} \mathrm{CFU} / \mathrm{kg}$ B. adolescentis. Each experimental group consisted of ten mice. The mice were treated with distilled water, amitriptyline (dissolved in distilled water), or $B$. adolescentis (dissolved in distilled water) by gavage for 21 days depending on the group. After 21 days, all mice underwent a behavioral test for three consecutive days (Figure 1).

\section{Experiment 2}

The mice were randomly allocated into three groups: the Con group, which received $10 \mathrm{~mL} / \mathrm{kg}$ distilled water; the CRS group, which was subjected to the CRS procedure and received $10 \mathrm{~mL} / \mathrm{kg}$ distilled water; and the Bif+CRS group, which was subjected to the CRS procedure and received $0.25 \times 10^{9} \mathrm{CFU} / \mathrm{kg}$ B. adolescentis. Each group consisted of twelve mice. The mice were treated with distilled water or $B$. adolescentis by gavage for 21 days depending on the group. For the CRS procedure, the mice were placed in a 50 - $\mathrm{mL}$ tube for $4 \mathrm{~h}$ for 21 consecutive days. The behavioral test procedure was performed as reported previously with few modifications (Yang et al., 2015). After 21 days, all mice underwent a behavioral test for four consecutive days (Figure 2). One day after the completion of the behavioral test, six mice from each group were anesthetized (6\% sodium pentobarbital, intraperitoneally) and subsequently sacrificed by decapitation. The whole hippocampus was quickly dissected and frozen in liquid nitrogen and stored at $-80^{\circ} \mathrm{C}$ for Western blotting (Figure 5). The cecal contents were collected and used for $16 \mathrm{~S}$ 

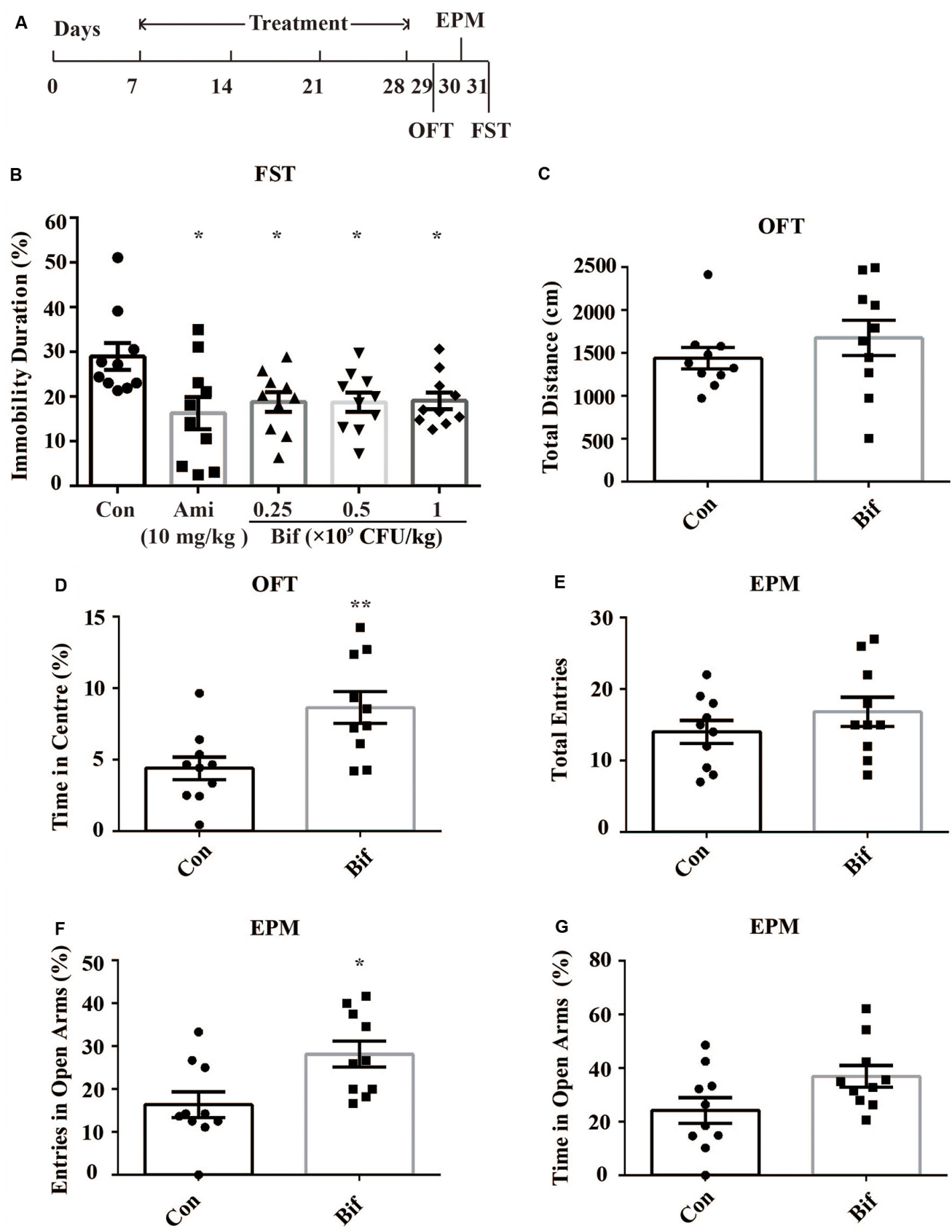

FIGURE 1 | Potential anxiolytic and antidepressant effects of B. adolescentis. The mice in the Con, Ami (10 mg/kg), Bif $\left(0.25 \times 10^{9} \mathrm{CFU} / \mathrm{kg}\right)$, Bif $\left(0.5 \times 10^{9}\right.$ $\mathrm{CFU} / \mathrm{kg})$, and Bif $\left(1 \times 10^{9} \mathrm{CFU} / \mathrm{kg}\right)$ groups were treated with $10 \mathrm{~mL} / \mathrm{kg}$ distilled water, $10 \mathrm{mg} / \mathrm{kg}$ amitriptyline, $0.25 \times 10^{9} \mathrm{CFU} / \mathrm{kg} \mathrm{B}$. adolescentis, $0.5 \times 10^{9}$ CFU/kg B. adolescentis, and $1 \times 10^{9} \mathrm{CFU} / \mathrm{kg} \mathrm{B}$. adolescentis, respectively, by gavage for 21 days. (A) The timeline of Experiment 1 . (B) The results of the FST showed that the immobility duration was significantly decreased in the Ami (10 mg/kg), Bif $\left(0.25 \times 10^{9} \mathrm{CFU} / \mathrm{kg}\right)$, Bif $\left(0.5 \times 10^{9} \mathrm{CFU} / \mathrm{kg}\right)$, and Bif $\left(1 \times 10^{9} \mathrm{CFU} / \mathrm{kg}\right)$ groups. (C) The OFT showed no significant difference between the control group and the Bif $\left(0.25 \times 10^{9} \mathrm{CFU} / \mathrm{kg}\right) \mathrm{group}$ in the total distance traveled. (D) The OFT showed that the time spent in the center was significantly increased in the Bif $\left(0.25 \times 10^{9} \mathrm{CFU} / \mathrm{kg}\right)$ group. (E) The EPM test showed no significant difference between the control group and the Bif $\left(0.25 \times 10^{9} \mathrm{CFU} / \mathrm{kg}\right)$ group in the total number of entries. (F) The number of entries into the open arms of the EPM was significantly increased in the Bif $\left(0.25 \times 10^{9} \mathrm{CFU} / \mathrm{kg}\right)$ group. (G) The EPM test showed no significant difference between the control group and the Bif $\left(0.25 \times 10^{9}\right.$ $\mathrm{CFU} / \mathrm{kg}$ ) group in time spent in the open arms. The data are shown as the mean \pm SEM. Student's $t$-test was used. ${ }^{*} p<0.05$ and ${ }^{* *} p<0.01$ vs. control. Con, Control; Bif, B. adolescentis; FST, forced swimming test; OFT, open field test; EPM, elevated plus-maze. 

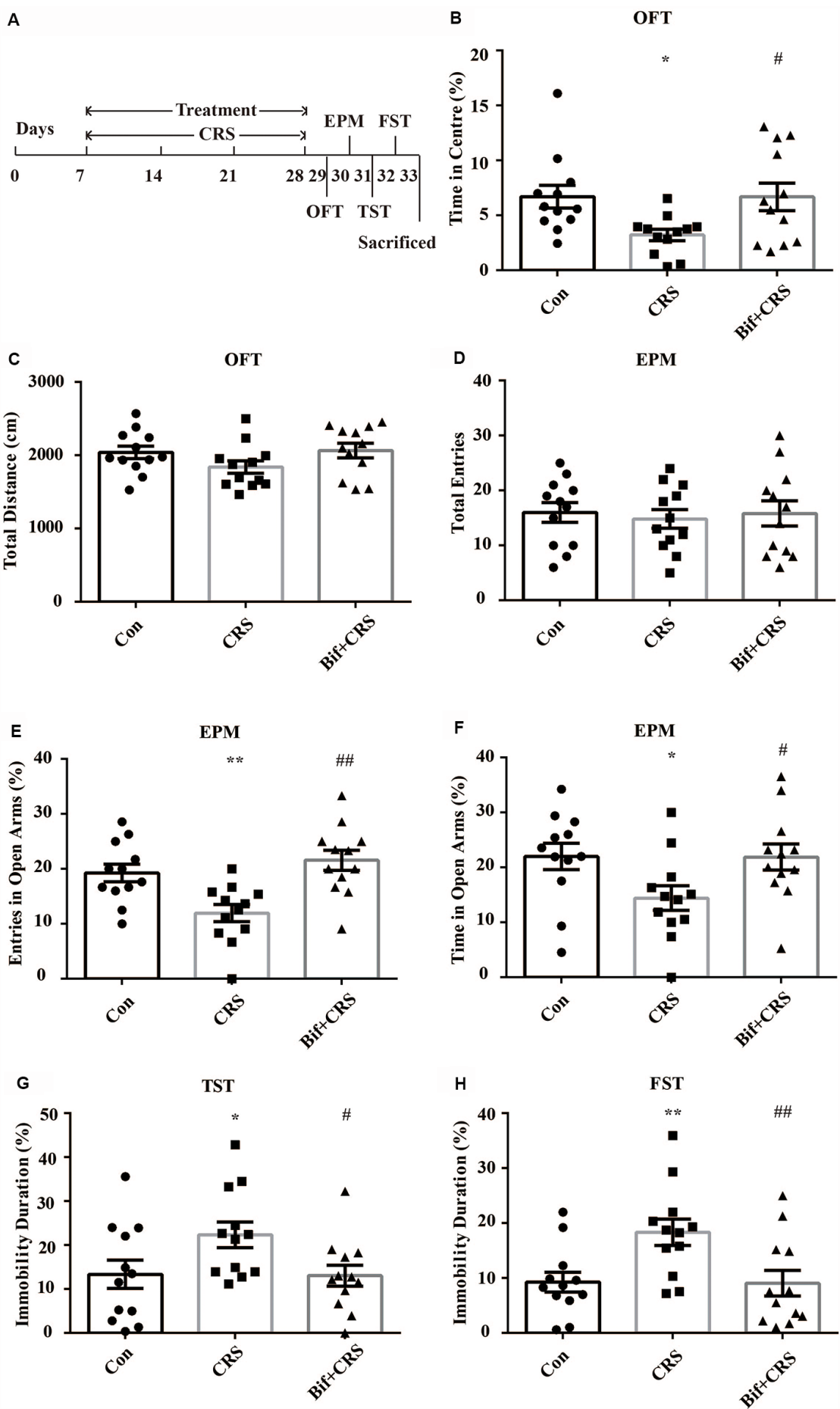

FIGURE 2 Anxiolytic and antidepressant effects of $B$. adolescentis in chronic restraint stress (CRS) mice. The mice in the Con, CRS, and Bif+CRS groups were treated with $10 \mathrm{~mL} / \mathrm{kg}$ distilled water, $10 \mathrm{~mL} / \mathrm{kg}$ distilled water, and $0.25 \times 10^{9} \mathrm{CFU} / \mathrm{kg} \mathrm{B}$. adolescentis, respectively, by gavage for 21 days. (A) The schedules show the establishment of the CRS model, treatment, and behavioral tests. (B) The OFT showed that the time spent in the center was significantly decreased in the CRS group, and the change in the time spent in the center induced by CRS was reversed by B. adolescentis. (C) The OFT showed no significant difference among the three groups in the total distance traveled. (D) The EPM test showed no significant difference in the total number of entries induced by $B$. adolescentis. (E) The number of entries into the open arms of the EPM was significantly increased in the $B$. adolescentis group. (F) The time spent in the open arms of the EPM was significantly increased in the B. adolescentis group. (G) The TST showed that the immobility duration was significantly increased in the CRS group; the change in the immobility duration induced by CRS was reversed by B. adolescentis. (H) The FST showed that the immobility duration was significantly increased in the CRS group; 
FIGURE 2 | Continued

the change in the immobility duration induced by CRS was reversed by B. adolescentis. The data are shown as the mean \pm SEM. One-way analysis of variance (ANOVA) followed by the Student-Newman-Keuls test was used. ${ }^{*} p<0.05$ and ${ }^{* *} p<0.01$ vs. the control; ${ }^{\#} p<0.05$ and ${ }^{\# \#} p<0.01$ vs. the CRS group; $n=12$ per group. Con, Control; CRS, chronic restraint stress; Bif+CRS, B. adolescentis + chronic restraint stress; OFT, open field test; EPM, elevated plus-maze; TST, tail suspension test; FST, forced swimming test.

rRNA sequence analysis (Figures 3, 4). After deep anesthesia with $6 \%$ sodium pentobarbital, six mice from each group were perfused with $4 \%$ paraformaldehyde for immunofluorescence labeling (Figure 6).

\section{CRS}

To establish the CRS model, the mice were placed in a horizontal resting position inside a well-ventilated (12 holes and $0.5 \mathrm{~mm}$ in diameter) $50-\mathrm{mL}$ tube for $4 \mathrm{~h}$ for 21 consecutive days (Wong et al., 2016).

\section{ANTIBODIES AND REAGENTS}

Rabbit anti-brain-derived neurotrophic factor (BDNF) antibody, rabbit anti-ionized calcium binding adapter molecule 1 (Iba1) antibody, and rabbit anti-IL-1 $\beta$ antibody were acquired from Abcam (Shanghai, China). Rabbit anti-TNF- $\alpha$, rabbit anti-

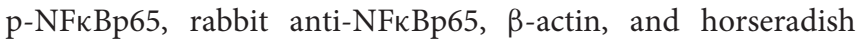
peroxidase (HRP)-conjugated anti-rabbit IgG antibodies were obtained from Cell Signaling Technology (Boston, MA, USA). An E.Z.N.A. Stool DNA Kit was acquired from Omega Bio-Tek (Norcross, GA, USA). An AxyPrep DNA Gel Extraction Kit was obtained from Axygen Biosciences (Union City, CA, USA). Live B. adolescentis AY240946 was purchased from Lizhu Pharmaceutical Factory (Guangdong, China).

\section{Behavioral Tests}

The illumination in the testing room was controlled, providing 60 lux inside the apparatus. Thirty minutes before the tests, each mouse was brought into the testing laboratory. The behavioral tests were carried out between 9:00 and 13:00.

\section{Open Field Test (OFT)}

The open field apparatus was a box $(50 \times 50 \times 28 \mathrm{~cm})$ with a floor divided into 25 squares. The nine central squares were defined as the center. On the day of the OFT, each mouse was gently placed in the center of the open field, and its movements were digitally recorded by video tracking software Smart V3.0 (Panlab, Spain) over a 6-min trial.

\section{Elevated Plus-Maze (EPM) Test}

On the day of the EPM test, each mouse was gently placed in the center of the EPM. The EPM was elevated $50 \mathrm{~cm}$ above the floor and consisted of two open arms $(31 \times 7.8 \mathrm{~cm})$, two enclosed arms $(31 \times 6.5 \times 11 \mathrm{~cm})$ with walls, and a central area $(7.8 \times 6.5 \mathrm{~cm})$. Movements were measured over a 6-min trial by Smart V3.0.

\section{Tail Suspension Test (TST)}

On the day of the tail suspension test, the mice were suspended upside down by their tails $40 \mathrm{~cm}$ above the floor, and an adhesive tape was placed $1 \mathrm{~cm}$ from the tail tip. The testing period was 6 min long, and the immobility time was analyzed over the last 4 min by Smart V3.0.

\section{Forced Swimming Test (FST)}

On the day of the FST, the mice were placed in a vertical transparent cylinder $(30 \mathrm{~cm}$ in height and $12 \mathrm{~cm}$ in diameter) containing tap water at $25 \pm 1^{\circ} \mathrm{C}$ and $20 \mathrm{~cm}$ in depth. The testing period was 6 min long, and the immobility time of each mouse was scored over the last $4 \mathrm{~min}$ by Smart V3.0.

\section{Analysis of Cecal Microflora Community Diversity}

Previously described procedures (Ravel et al., 2011) were used. For $16 \mathrm{~S}$ rRNA sequence analysis, DNA was extracted and then amplified to target the V1-V3 region with indexes and the adaptor-linked universal primers 27F (5'-AGAGTTTGATCCTGGCTCAG-3') and 533R (5'TTACCGCGGCTGCTGGCAC-3'). Amplicons were extracted, purified, and quantified by QuantiFluor-ST (Promega, San Luis Obispo, CA, USA). The purified amplicons were tagged with nucleotide barcodes, pooled in equimolar quantities and paired-end sequenced $(2 \times 300 \mathrm{bp})$ on an Illumina MiSeq platform. The raw fastq files were de-multiplexed, qualityfiltered with Trimmomatic (Version 3.29), and merged with FLASH (version 1.2.7). Operational taxonomic units (OTUs) were collected with a $97 \%$ similarity cut-off by UPARSE (version $7.1^{1}$ ), and chimeric sequences were identified and removed by UCHIME. The taxonomy of each $16 \mathrm{~S}$ rRNA gene sequence was analyzed by the RDP Classifier algorithm ${ }^{2}$ against the Silva (SSU128) 16S rRNA database with a confidence threshold of $70 \%$. The data were analyzed on the free online platform called Majorbio I-Sanger Cloud Platform ${ }^{3}$.

\section{Western Blotting of the Hippocampus (Yuan et al., 2014)}

Samples were homogenized with a protein extraction reagent containing protease inhibitors, and the concentrations of the proteins were determined using a BCA protein concentration assay kit. The proteins were separated by sodium dodecyl sulfate poly-acrylamide gel electrophoresis in a Mini-Protein II apparatus (Bio-Rad, CA, USA). The protein bands were electro-blotted onto a polyvinylidene fluoride membrane, and the membranes were blocked. The membranes were incubated with primary antibodies against BDNF $(1: 1,000)$, IL$1 \beta$ (1:1,000), Ibal (1:1,000), TNF- $\alpha(1: 1,000)$, p-NF-кB p65 $(1: 1,000)$, and NF-кB p65 (1:1,000) overnight at $4^{\circ} \mathrm{C}$. They were further incubated with a HRP-conjugated anti-rabbit IgG $(1: 5,000)$ antibody and then developed with ECL reagents. The different blots were incubated with different antibodies. As much of the proteins, which had different molecular weights, as possible were transferred to a single membrane, and then the blots were cut at different molecular weights and incubated with different antibodies according to the

\footnotetext{
${ }^{1}$ http://drive5.com/uparse/

${ }^{2}$ http://rdp.cme.msu.edu/

${ }^{3}$ www.i-sanger.com
} 

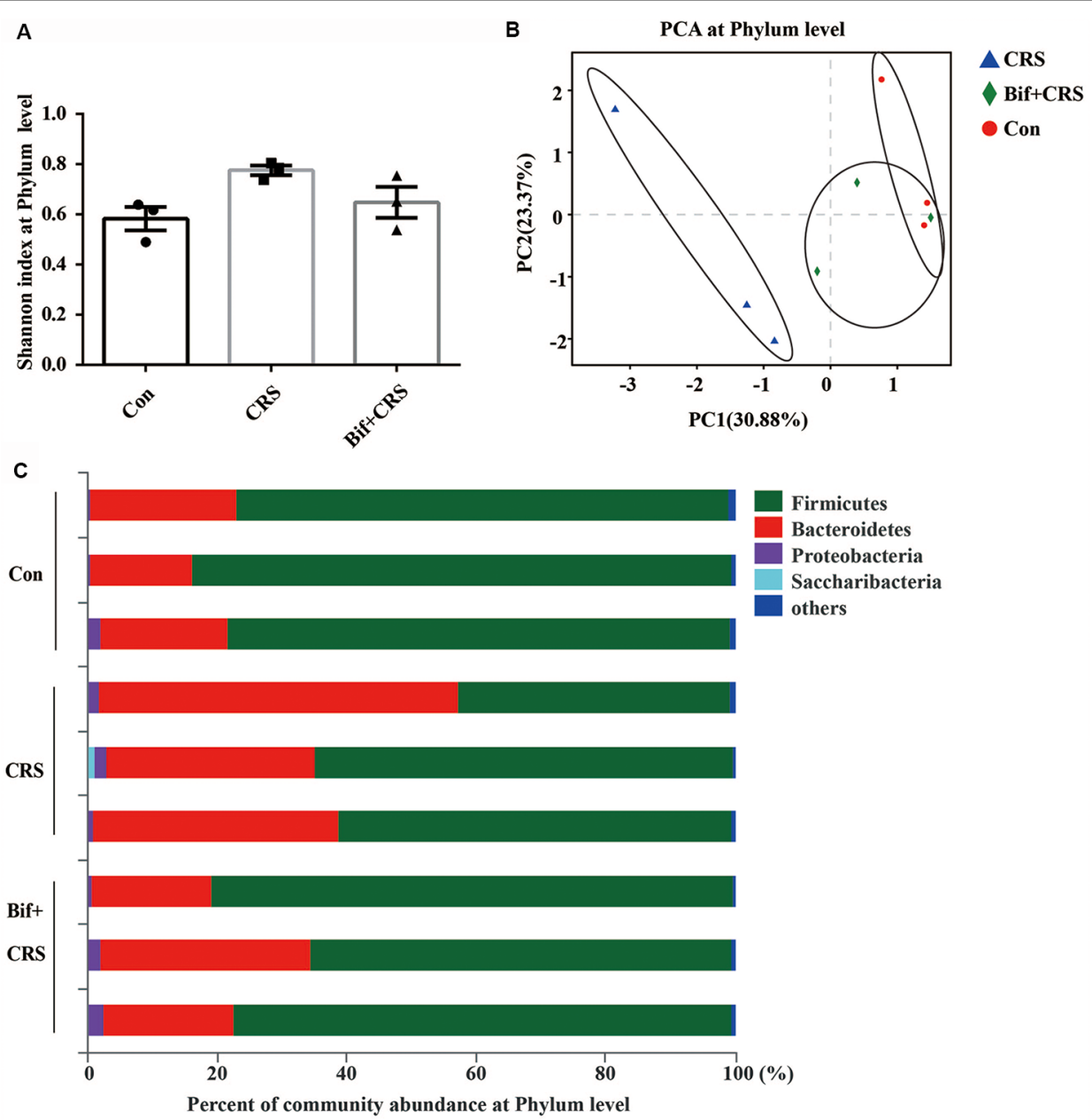

D

Firmicutes

E
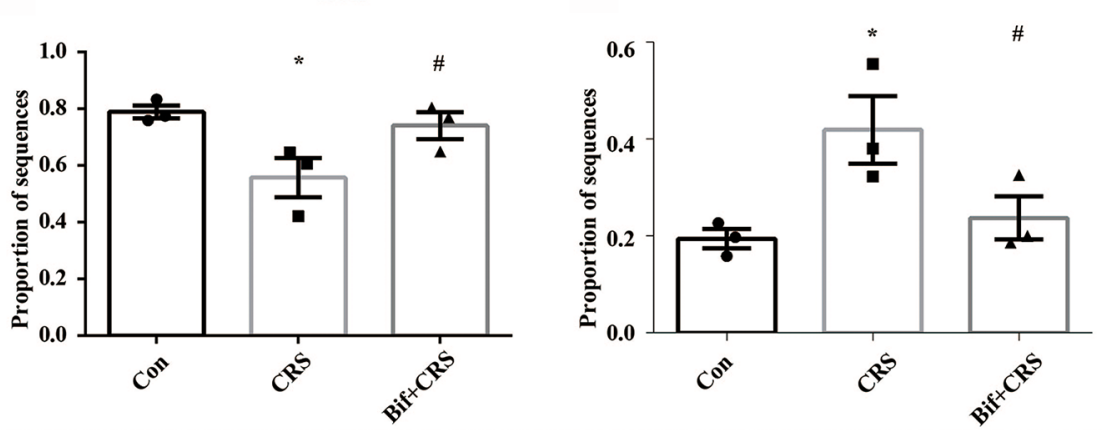

FIGURE 3 | B. adolescentis reversed the imbalance of the intestinal microflora induced by CRS at the phylum level. The mice in the Con, CRS, and Bif+CRS groups were given $10 \mathrm{~mL} / \mathrm{kg}$ distilled water, $10 \mathrm{~mL} / \mathrm{kg}$ distilled water, and $0.25 \times 10^{9} \mathrm{CFU} / \mathrm{kg} B$. adolescentis, respectively, by gavage for 21 days. (A) There was no significant difference in the Shannon index at the phylum level induced by B. adolescentis. (B) The principal component analysis (PCA) results showed no significant difference in the microbial community composition. (C) Community barplot analysis showed the community composition and species abundance in the three groups. (D) The decrease in Firmicutes abundance in the CRS group was enhanced by B. adolescentis. (E) The increased Bacteroidetes abundance in the CRS group was decreased by $B$. adolescentis. The data are shown as the mean \pm SEM. One-way ANOVA followed by the Student-Newman-Keuls test was used. ${ }^{*} p<0.05$ vs. the control; $" p<0.05$ vs. the CRS group; $n=3$ per group. Con, Control; CRS, chronic restraint stress; Bif+CRS, $B$. adolescentis + chronic restraint stress.

molecular weight of the target proteins. The target protein band was compared with the $\beta$-actin band on the same membrane. The chemiluminescence signal was imaged using a ChemiDoc XRS system (Bio-Rad) and the protein band signals were measured using ImageJ 1.4.3.67 software. The signal intensities of the individual protein bands were normalized to the $\beta$-actin band intensity and were represented by arbitrary units. 

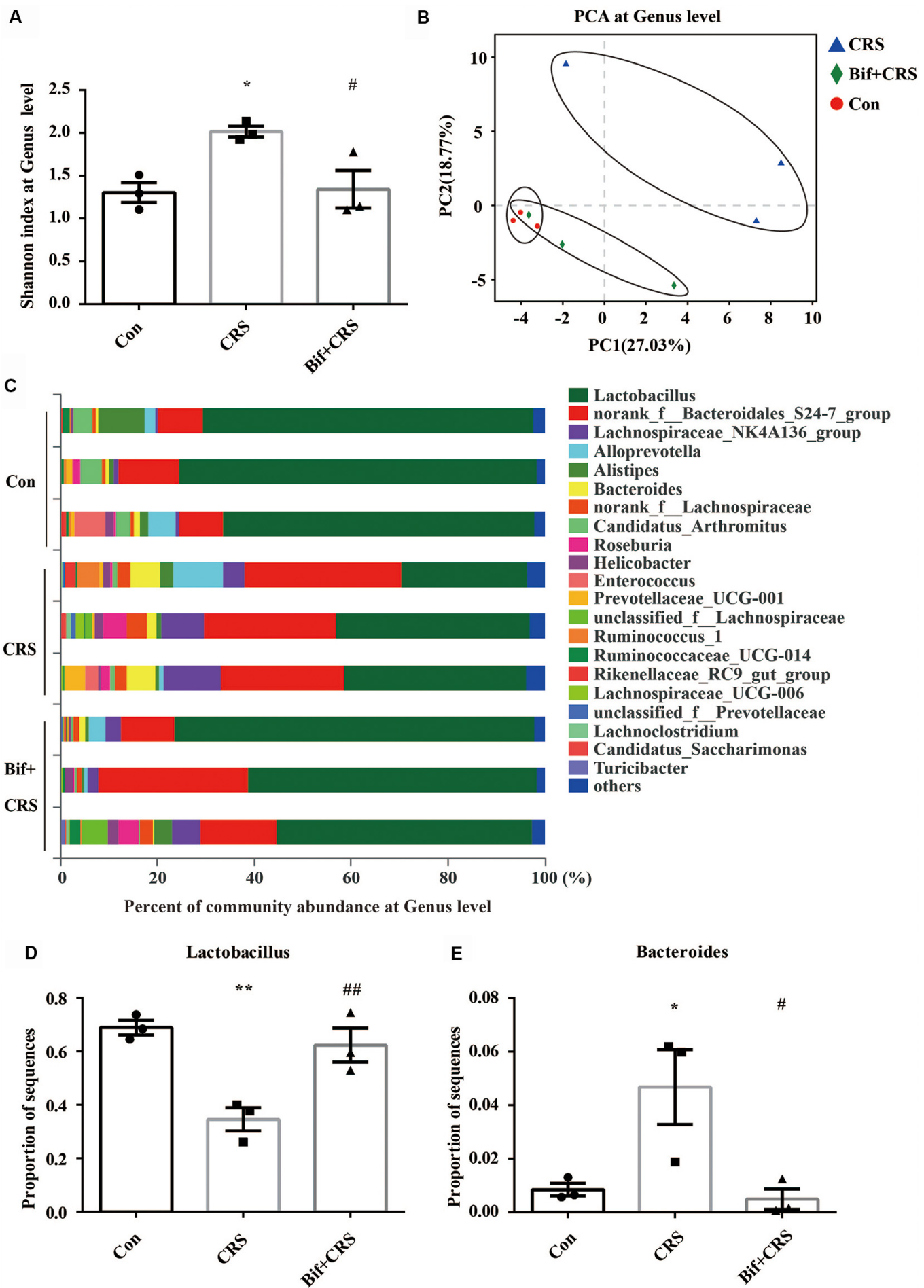

FIGURE 4 | B. adolescentis reversed the imbalance of the intestinal microflora induced by CRS at the genus level. The mice in the Con, CRS, and Bif+CRS groups were treated with $10 \mathrm{~mL} / \mathrm{kg}$ distilled water, $10 \mathrm{~mL} / \mathrm{kg}$ distilled water, and $0.25 \times 10^{9} \mathrm{CFU} / \mathrm{kg}$ B. adolescentis, respectively, by gavage for 21 days. (A) An increased Shannon index was observed in the CRS group compared with the control group, and the increase in the index was attenuated by $B$. adolescentis. (B) PCA revealed that the microbial community composition in the B. adolescentis group was more similar to that in the control than that in the CRS group, as shown by the clustering of the samples in the plots. (C) Community barplot analysis is shown. (D) The decrease in the Lactobacillus abundance in the CRS group was increased by B. adolescentis. (E) The enhanced Bacteroides abundance in the CRS group was reversed by $B$. adolescentis. The data are shown as the mean \pm SEM. One-way ANOVA followed by the Student-Newman-Keuls test was used. ${ }^{*} p<0.05$ and ${ }^{* *} p<0.01$ vs. the control; ${ }^{*} p<0.05$ and ${ }^{\# \#} p<0.01$ vs. the CRS group; $n=3$ per group. Con, Control; CRS, chronic restraint stress; Bif+CRS, B. adolescentis + chronic restraint stress. 


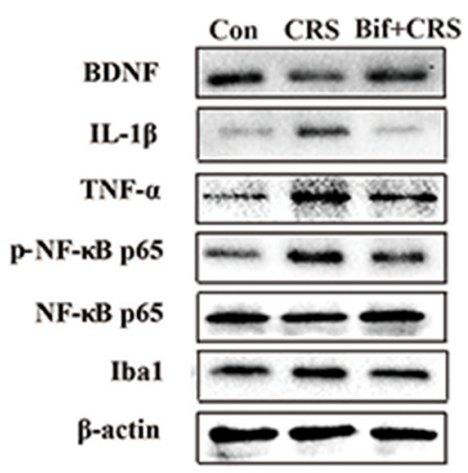

C

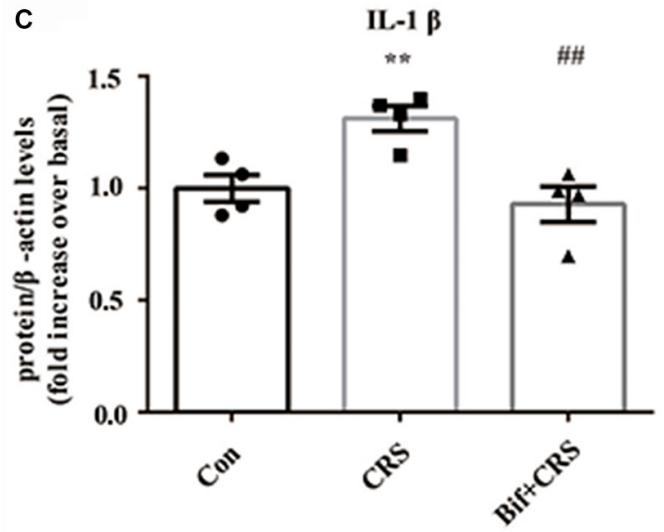

$E$

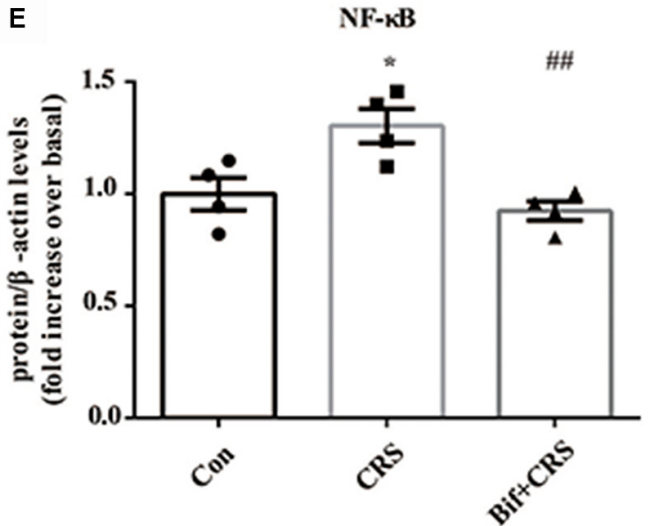

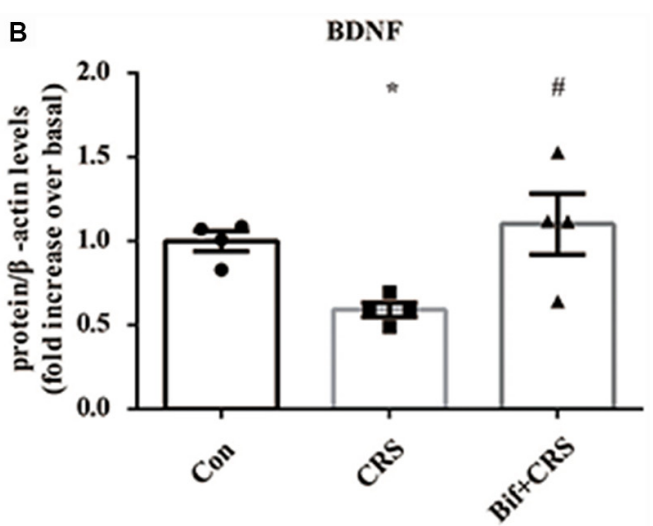

D

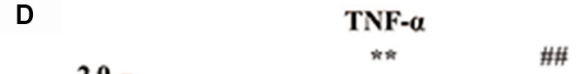

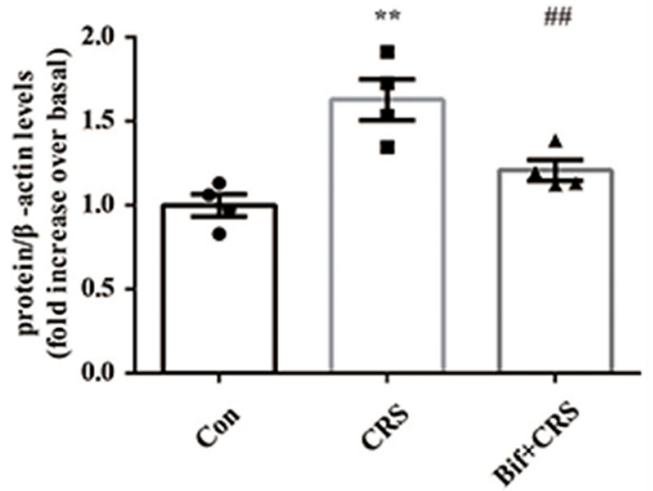

F Iba1

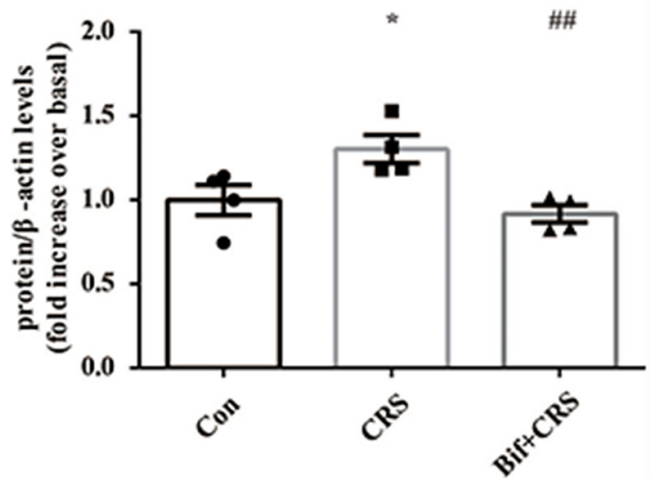

FIGURE 5 | Changes in the protein expression of BDNF, IL-1 $\beta$, TNF- $\alpha$, p-NF-kB p65 and lba1 in the hippocampus induced by pretreatment with B. adolescentis. The mice in the Con, CRS, and Bif+CRS groups were treated with $10 \mathrm{~mL} / \mathrm{kg}$ distilled water, $10 \mathrm{~mL} / \mathrm{kg}$ distilled water, and $0.25 \times 10^{9} \mathrm{CFU} / \mathrm{kg} B$. adolescentis, respectively, by gavage for 21 days. (A) Western blotting showed that (B) the protein level of BDNF was upregulated by $B$. adolescentis, and the protein levels of (C) IL-1 $\beta$, (D) TNF- $\alpha$, (E) p-NF-kB p65 and (F) Iba1 in the hippocampus were obviously suppressed by $B$. adolescentis. The data are shown as the mean \pm SEM. One-way ANOVA followed by the Student-Newman-Keuls test was used. ${ }^{*} p<0.05$ and ${ }^{* *} p<0.01$ vs. the control; ${ }^{\#} p<0.05$ and ${ }^{\# \#} p<0.01$ vs. the CRS group; $n=4$ per group. Con, Control; CRS, chronic restraint stress; Bif+CRS, B. adolescentis + chronic restraint stress; BDNF, brain derived neurotrophic factor; IL-1 $\beta$, interleukin-1 $\beta$; TNF- $\alpha$, tumor necrosis factor $\alpha$; NF-kB, nuclear factor-kappa B; Iba1, ionized calcium binding adapter molecule 1.

\section{Immunofluorescence Labeling in the Hippocampus (Fang et al., 2015)}

The brains were removed and embedded in paraffin. Coronal sections of $7 \mu \mathrm{m}$ thickness were cut using a microtome (Model: CUT5062; Mainz, SLEE, Germany), and the sections were blocked in $5 \%$ goat serum for $1 \mathrm{~h}$ at room temperature $\left(22-24^{\circ} \mathrm{C}\right)$.
After the serum was discarded, the sections were incubated with primary antibodies against BDNF (1:100), TNF- $\alpha$ (1:100), IL-1 $\beta$ (1:100), and Iba1 (1:100) overnight at $4^{\circ} \mathrm{C}$. The sections were incubated with a Cy3-conjugated secondary antibody (1:200) for $1 \mathrm{~h}$ at room temperature and then mounted with a fluorescent mounting medium containing 4',6-diamidino-2-phenylindole 


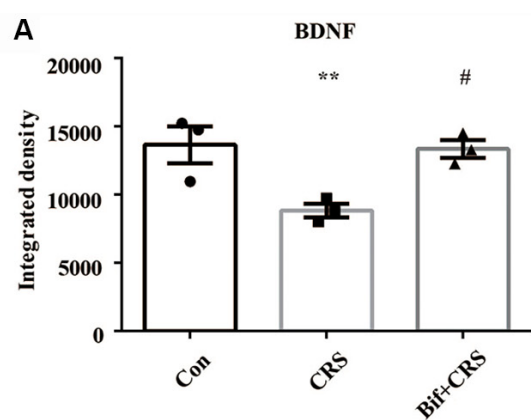

C
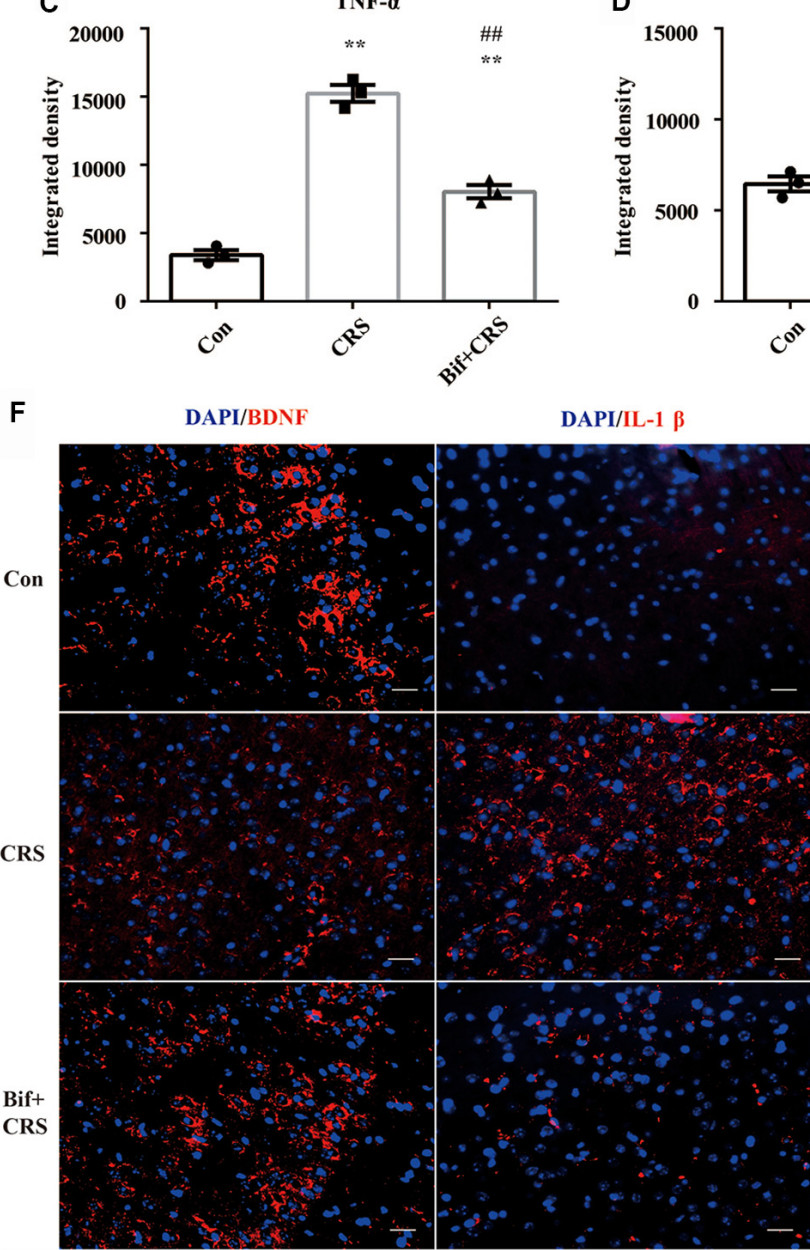

F
B

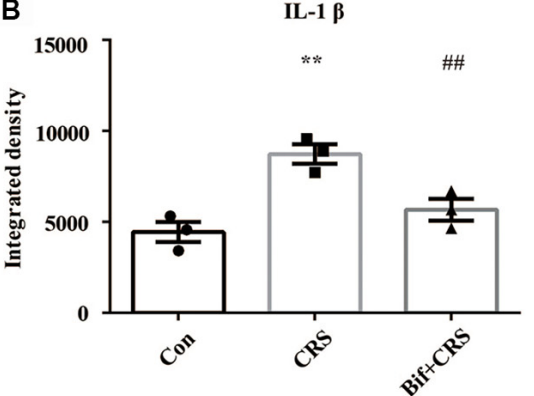

D

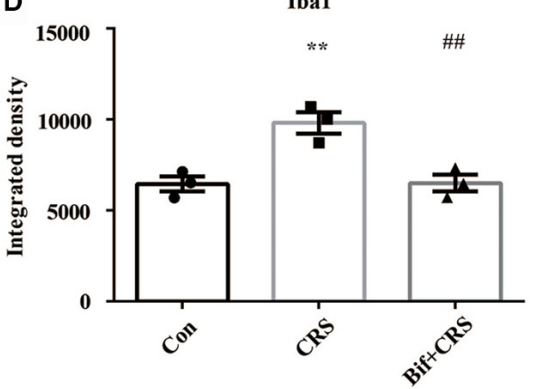

DAPI/TNF- $\alpha$.
E

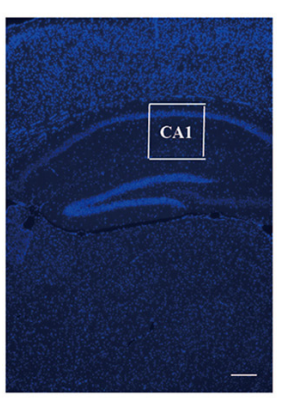

DAPI/Iba1

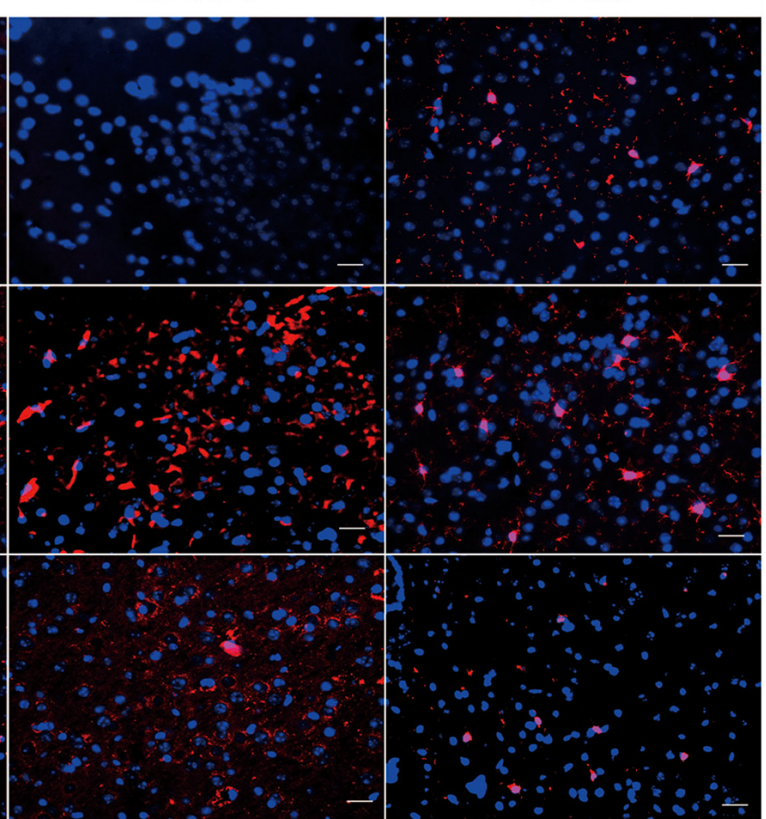

FIGURE 6 | Changes in the protein expression of BDNF, IL-1 $\beta$, TNF- $\alpha$, and Iba1 in the CA1 region of the hippocampus induced by pretreatment with $B$. adolescentis. Immunofluorescence analysis showed that $(\mathbf{A})$ the protein level of BDNF was upregulated by $B$. adolescentis, and the protein levels of (B) IL-1 $\beta$, (C) TNF- $\alpha$, and (D) Iba1 in the CA1 region of the hippocampus were obviously suppressed by $B$. adolescentis. The data are shown as the mean \pm SEM. One-way ANOVA followed by the Student-Newman-Keuls test was used. ${ }^{* *} p<0.01$ vs. the control; ${ }^{\#} p<0.05$ and ${ }^{\# \#} p<0.01$ vs. the CRS group; $n=3$ per group. (E) The CA1 region was identified as shown in the box. Scale bar $=200 \mu \mathrm{m}$. (F) Immunofluorescence was performed and subsequently visualized with Cy3 (red)-labeled secondary antibodies. DAPI (blue) was used as a nuclear stain. Scale bar $=20 \mu \mathrm{m}$. Con, Control; CRS, chronic restraint stress; Bif + CRS, B. adolescentis + chronic restraint stress; BDNF, brain derived neurotrophic factor; IL-1 $\beta$, interleukin-1 $\beta$; TNF- $\alpha$, tumor necrosis factor $\alpha$; Iba1, ionized calcium binding adapter molecule 1.

(DAPI). Eight successive slices from each mouse were used for immunofluorescence, and four successive slices (two arrays) were allocated for incubation with the different antibodies. The sections were subsequently observed by an inverted fluorescence microscope (Axio Observer. Z1, Zeiss, Germany). The CA1 region was assessed in the immunofluorescence and was represented on the template coronal slices from $1.70 \mathrm{~mm}$ to $1.94 \mathrm{~mm}$ inclusive, anterior to the bregma. The quantification 
of immunofluorescence intensity in the fluorescence images was expressed as integrated density, which was quantified using ImageJ software.

\section{Statistical Analysis}

All data are presented as the mean \pm standard error of mean (SEM). Statistical analyses were performed using a two-tailed Student's $t$-test or one-way analysis of variance (ANOVA) followed by a Student-Newman-Keuls post hoc test using SPSS 19.0 (SPSS Inc., Chicago, IL, USA). For the microbiota, the Adonis test was used to analyze the $B$ diversity in principal component analysis (PCA), and False Discovery Rate (FDR) was used to correct for multiple testing of the comparisons of specific genera. A $p$-value $<0.05$ was considered statistically significant.

\section{RESULTS}

\section{Potential Anxiolytic and Antidepressant Effects of $B$. adolescentis}

To preliminarily investigate the antidepressant effects of $B$. adolescentis, the FST was used. The immobility duration $\left(t_{18}=2.698, p=0.015 ; t_{18}=2.741, p=0.013 ; t_{18}=2.794\right.$, $p=0.012 ; t_{18}=2.824, p=0.011$; Figure 1B) was decreased significantly by amitriptyline $(10 \mathrm{mg} / \mathrm{kg})$ and $B$. adolescentis $\left(0.25 \times 10^{9} \mathrm{CFU} / \mathrm{kg}, 0.5 \times 10^{9} \mathrm{CFU} / \mathrm{kg}\right.$, and $\left.1 \times 10^{9} \mathrm{CFU} / \mathrm{kg}\right)$. The OFT and the EPM were used to evaluate spontaneous activity and the anxiolytic effects of $B$. adolescentis. The total distance traveled in the OFT $\left(t_{18}=-0.995, p=0.333\right.$, Figure 1C) did not significantly differ between the control group and the B. adolescentis-treated $\left(0.25 \times 10^{9} \mathrm{CFU} / \mathrm{kg}\right)$ group, and the time spent in the center of the OFT apparatus $\left(t_{18}=-3.11\right.$, $p=0.006$, Figure 1D) was increased by $B$. adolescentis $\left(0.25 \times 10^{9}\right.$ $\mathrm{CFU} / \mathrm{kg}$ ). Moreover, the total number of entries into the arms of the EPM $\left(t_{18}=-1.087, p=0.292\right.$, Figure 1E) did not differ between the control group and the $B$. adolescentistreated $\left(0.25 \times 10^{9} \mathrm{CFU} / \mathrm{kg}\right)$ group. B. adolescentis $\left(0.25 \times 10^{9}\right.$ $\mathrm{CFU} / \mathrm{kg}$ ) increased the percentage of entries into the open arms of the EPM $\left(t_{18}=-2.768, p=0.013\right.$, Figure 1F). However, B. adolescentis $\left(0.25 \times 10^{9} \mathrm{CFU} / \mathrm{kg}\right)$ did not increase the percentage of time spent in the open arms of EPM $\left(t_{18}=-2.018, p=0.059\right.$, Figure 1G). These data (Table 1) indicate the potential anxiolytic and antidepressant effects of $B$. adolescentis.

\section{Anxiolytic and Antidepressant Effects of B. adolescentis in CRS Mice}

To further investigate the anxiolytic and antidepressant effects of $B$. adolescentis, a CRS model was used, as shown in the schedule (Figure 2A). There was a significant difference in the time spent in the center of the OFT apparatus $\left(F_{(2,33)}=4.183\right.$, $p=0.024$, Figure $2 B$ ). The time spent in the center of the OFT apparatus was decreased in the CRS group compared with the control group $(p<0.05)$, and the $B$. adolescentis group spent a significantly longer time in the center than that spent by the CRS group $(p<0.05)$. There were no remarkable changes among the three groups in the total distance traveled in the OFT $\left(F_{(2,33)}=1.875, p=0.169\right.$, Figure 2C). The EPM test showed no significant difference between the two groups in the total number of entries $\left(F_{(2,33)}=0.104, p=0.901\right.$, Figure 2D). $B$. adolescentis increased the percentage of entries into the open arms of the $\operatorname{EPM}\left(F_{(2,33)}=9.108, p=0.001\right.$, Figure 2E) and the percentage of time spent in the open arms of the EPM $\left(F_{(2,33)}=3.465, p=0.043\right.$, Figure $\left.2 F\right)$. Both the percentage of entries into the open arms of the EPM $(p<0.01)$ and the percentage of time spent in the open arms of the EPM $(p<0.05)$ were decreased in the CRS group compared with the control group. Both percentages $(p<0.01, p<0.05)$ were increased in the $B$. adolescentis group compared with the CRS group. There was a significant difference in the immobility durations in the TST $\left(F_{(2,33)}=3.422, p=0.045\right.$, Figure 2G) and the FST $\left(F_{(2,33)}=5.78, p=0.007\right.$, Figure $\left.2 \mathbf{H}\right)$. The results showed markedly increased immobility durations in the CRS mice in both the TST $(p<0.05)$ and the FST $(p<0.01)$. Decreased immobility durations were observed in both the TST $(p<0.05)$ and the FST $(p<0.01)$ in the $B$. adolescentis group compared with the CRS group. Altogether, these data (Table 2) indicate that B. adolescentis has anxiolytic and antidepressant effects on CRS mice in these behavioral tests.

\section{B. adolescentis Reversed the Imbalance of Cecal Microflora Induced by CRS}

To test the assumption that the anxiolytic and antidepressant effects of $B$. adolescentis are related to rebalancing the gut microbiota, cecal microflora community diversity was analyzed. There was no significant difference in the Shannon index at the phylum level $\left(F_{(2,6)}=4.5, p=0.064\right.$, Figure 3A). PCA revealed that there was no significant difference in the microbial community composition of the three groups at the phylum level $\left(R^{2}=0.53264, p=0.108\right.$, Figure 3B). Community barplot analysis showed the community composition and species abundance in the three groups (Figure 3C). Further analysis showed a significant difference in the abundance of Firmicutes $\left(F_{(2,6)}=5.946, p=0.038\right.$, Figure 3D) and Bacteroidetes $\left(F_{(2,6)}=5.9, p=0.038\right.$, Figure 3E) at the phylum level. The decline $(p<0.05)$ in Firmicutes abundance in the CRS group was enhanced $(p<0.05)$ by $B$. adolescentis. Additionally, the previous increase $(p<0.05)$ in Bacteroidetes in the CRS group was decreased $(p<0.05)$ by B. adolescentis (Table 3$)$.

For the further verification of cecal microflora community diversity, Shannon index, principal component and community barplot analyses were performed at the genus level. There was a significant difference in the Shannon index at the genus level $\left(F_{(2,6)}=7.294, p=0.025\right.$, Figure 4A). An increased Shannon index $(p<0.05)$ was observed in the CRS group compared with the control group, and the increase in the index was attenuated $(p<0.05)$ by $B$. adolescentis. PCA revealed that the microbial community composition in the $B$. adolescentis group was more similar to that in the control group than that in the CRS group, as shown by the clustering of the samples in the plots $\left(R^{2}=0.54811\right.$, $p=0.008$, Figure 4B). Community barplot analysis is shown in Figure 4C. Significant differences in the abundance of Lactobacillus $\left(F_{(2,6)}=14.997, p=0.005\right.$, Figure 4D) and Bacteroides $\left(F_{(2,6)}=7.488, p=0.023\right.$, Figure $\left.4 \mathrm{E}\right)$ are shown. 
TABLE 1 | Potential anxiolytic and antidepressant effects of $B$. adolescentis.

\begin{tabular}{|c|c|c|c|c|c|c|c|c|c|c|c|c|c|c|}
\hline \multicolumn{5}{|c|}{ B. Immobility Duration of Forced swimming test (\%) } & \multicolumn{2}{|c|}{$\begin{array}{l}\text { C. Total Distance of } \\
\text { Open Field }(\mathrm{cm})\end{array}$} & \multicolumn{2}{|c|}{$\begin{array}{l}\text { D. Time in Center } \\
\text { of Open Field (\%) }\end{array}$} & \multicolumn{2}{|c|}{$\begin{array}{l}\text { E. Total Entries of } \\
\text { EPM }\end{array}$} & \multicolumn{2}{|c|}{$\begin{array}{l}\text { F. Entries in Open } \\
\text { Arms of EPM (\%) }\end{array}$} & \multicolumn{2}{|c|}{$\begin{array}{l}\text { G. Time in Open } \\
\text { Arms of EPM (\%) }\end{array}$} \\
\hline Con & $\begin{array}{c}\text { Ami } \\
(10 \mathrm{mg} / \mathrm{kg})\end{array}$ & $\begin{array}{l}\text { Bif }\left(0.25 \times 10^{9}\right. \\
\text { CFU } / \mathrm{kg})\end{array}$ & $\begin{array}{l}\text { Bif }\left(0.5 \times 10^{9}\right. \\
\text { CFU/kg) }\end{array}$ & $\begin{array}{l}\text { Bif }\left(1 \times 10^{9}\right. \\
\text { CFU/kg) }\end{array}$ & Con & $\begin{array}{l}\text { Bif }\left(0.25 \times 10^{9}\right. \\
\text { CFU } / \mathrm{kg})\end{array}$ & Con & $\begin{array}{l}\text { Bif }\left(0.25 \times 10^{9}\right. \\
\text { CFU } / \mathrm{kg})\end{array}$ & Con & $\begin{array}{c}\text { Bif }\left(0.25 \times 10^{9}\right. \\
\text { CFU } / \mathrm{kg})\end{array}$ & Con & $\begin{array}{c}\text { Bif }\left(0.25 \times 10^{9}\right. \\
\text { CFU/kg) }\end{array}$ & Con & $\begin{array}{c}\text { Bif }\left(0.25 \times 10^{9}\right. \\
\text { CFU } / \mathrm{kg})\end{array}$ \\
\hline 39.17 & 2.5 & 28.89 & 22.22 & 16.69 & 1263.21 & 2053.69 & 4.43 & 7.34 & 15 & 10 & 26.67 & 20.00 & 32.24 & 26.28 \\
\hline 27.78 & 4.44 & 23.17 & 12.5 & 14.81 & 1595.11 & 2465.83 & 4.67 & 12.69 & 14 & 8 & 14.29 & 37.50 & 14.92 & 35.56 \\
\hline 21.94 & 23.06 & 11.11 & 29.72 & 17.08 & 1121.71 & 1635.51 & 2.51 & 9.32 & 16 & 26 & 12.50 & 34.62 & 18.52 & 62.16 \\
\hline 21.39 & 3.06 & 22.08 & 7.22 & 13.97 & 1242.33 & 2493.29 & 2.44 & 12.36 & 8 & 18 & 12.50 & 16.67 & 33.28 & 34.88 \\
\hline 30.56 & 10.56 & 6.39 & 25 & 12.67 & 1382.98 & 504.9 & 5.37 & 8.56 & 19 & 12 & 0.00 & 41.67 & 0 & 54.24 \\
\hline 23.06 & 31.11 & 25.83 & 13.06 & 30.67 & 1480.85 & 971.53 & 9.64 & 4.28 & 18 & 15 & 11.11 & 40.00 & 10.24 & 31.48 \\
\hline 24.44 & 14.17 & 12.78 & 23.33 & 15.47 & 1577.51 & 1446.7 & 0.45 & 6.13 & 7 & 22 & 14.29 & 18.18 & 26.4 & 42.32 \\
\hline 51.11 & 18.06 & 20.28 & 15.83 & 20.27 & 972.73 & 2119.14 & 3.35 & 4.21 & 9 & 27 & 33.33 & 25.93 & 42.52 & 32.76 \\
\hline 23.06 & 35 & 18.06 & 18.61 & 26.53 & 2412.68 & 1785.53 & 6.4 & 14.25 & 22 & 15 & 13.64 & 20.00 & 14.72 & 28 \\
\hline 27.22 & 21.11 & 19.72 & 20 & 22.42 & 1324.97 & 1272.91 & 4.65 & 7.2 & 12 & 15 & 25.00 & 26.67 & 48.6 & 20.52 \\
\hline \multicolumn{5}{|c|}{ compared with control $t$-test for Equality of Means } & \multicolumn{2}{|c|}{$\begin{array}{l}\text { compared with control } \\
t \text {-test for Equality of Means }\end{array}$} & \multicolumn{2}{|c|}{$\begin{array}{l}\text { compared with control } \\
t \text {-test for Equality of Means }\end{array}$} & \multicolumn{2}{|c|}{$\begin{array}{l}\text { compared with control } \\
t \text {-test for Equality of Means }\end{array}$} & \multicolumn{2}{|c|}{$\begin{array}{l}\text { compared with control } \\
\text { t-test for Equality of Means }\end{array}$} & \multicolumn{2}{|c|}{$\begin{array}{l}\text { compared with control } \\
t \text {-test for Equality of Means }\end{array}$} \\
\hline \multirow{3}{*}{\multicolumn{2}{|c|}{$\begin{array}{c}p=0.015 \\
d f=18 \\
t=2.698\end{array}$}} & 0.013 & 0.012 & 0.011 & \multicolumn{2}{|c|}{$p=0.333$} & & \multicolumn{2}{|c|}{0.292} & \multicolumn{2}{|c|}{0.013} & \multirow{2}{*}{\multicolumn{2}{|c|}{$\begin{array}{c}0.059 \\
d f=18\end{array}$}} \\
\hline & & 18 & 18 & 18 & \multicolumn{2}{|c|}{$d f=18$} & \multicolumn{2}{|r|}{$d f=18$} & \multicolumn{2}{|r|}{$d f=18$} & \multicolumn{2}{|r|}{$d f=18$} & & \\
\hline & & 2.741 & 2.794 & 2.824 & \multicolumn{2}{|c|}{$=-0.995$} & \multicolumn{2}{|r|}{$t=-3.11$} & \multicolumn{2}{|r|}{$t=-1.087$} & \multicolumn{2}{|r|}{$t=-2.768$} & \multicolumn{2}{|r|}{$t=-2.018$} \\
\hline
\end{tabular}

The mice in groups of Con, Ami (10 mg/kg), Bif( $\left(0.25 \times 10^{9} \mathrm{CFU} / \mathrm{kg}\right)$, Bif $\left(0.5 \times 10^{9} \mathrm{CFU} / \mathrm{kg}\right)$ and Bif $\left(1 \times 10^{9} \mathrm{CFU} / \mathrm{kg}\right)$ were given with distilled water $(10 \mathrm{~mL} / \mathrm{kg})$, amitriptyline $(10 \mathrm{mg} / \mathrm{kg})$, B. adolescentis $\left(0.25 \times 10^{9} \mathrm{CFU} / \mathrm{kg}\right)$, B. adolescentis $\left(0.5 \times 10^{9} \mathrm{CFU} / \mathrm{kg}\right)$ and $\mathrm{B}$. adolescentis $\left(1 \times 10^{9} \mathrm{CFU} / \mathrm{kg}\right)$ respectively, by gavage for 21 days. $N=10$ per group.

TABLE 2 | Anxiolytic and antidepressant effects of $B$. adolescentis in CRS mice.

\begin{tabular}{|c|c|c|c|c|c|c|c|c|c|c|c|c|c|c|c|c|c|c|c|c|}
\hline \multicolumn{3}{|c|}{$\begin{array}{l}\text { B. Time in Center of } \\
\text { Open Field (\%) }\end{array}$} & \multicolumn{3}{|c|}{$\begin{array}{l}\text { C. Total Distance of Open Field } \\
\qquad(\mathrm{cm})\end{array}$} & \multicolumn{3}{|c|}{ D. Total Entries of EPM } & \multicolumn{3}{|c|}{$\begin{array}{l}\text { E. Entries in Open Arms } \\
\text { of EPM (\%) }\end{array}$} & \multicolumn{3}{|c|}{$\begin{array}{c}\text { F. Time in Open Arms of } \\
\text { EPM (\%) }\end{array}$} & \multicolumn{3}{|c|}{$\begin{array}{l}\text { G. Immobility Duration of } \\
\text { Tail Suspension Test (\%) }\end{array}$} & \multicolumn{3}{|c|}{$\begin{array}{l}\text { H. Immobility Duration of } \\
\text { Forced swimming test (\%) }\end{array}$} \\
\hline Con & CRS & $\mathrm{Bif}+\mathrm{CRS}$ & Con & CRS & $\mathrm{Bif}+\mathrm{CRS}$ & Con & CRS & $\mathrm{Bif}+\mathrm{CRS}$ & Con & CRS & Bif+CRS & Con & CRS & $\mathrm{Bif}+\mathrm{CRS}$ & Con & CRS & $\mathrm{Bif}+\mathrm{CRS}$ & Con & CRS & Bif+CRS \\
\hline 5.39 & 0.32 & 2.6 & 1941.64 & 1658.32 & 1543.94 & 15 & 13 & 8 & 20.00 & 15.38 & 25.00 & 21.32 & 16.32 & 23.17 & 22.05 & 34.53 & 11.55 & 5.9 & 19.33 & 15.18 \\
\hline 5.81 & 2.84 & 12.29 & 1977.99 & 1462.89 & 2161.88 & 19 & 21 & 14 & 26.32 & 14.29 & 28.57 & 25.44 & 24.48 & 36.54 & 2.82 & 42.82 & 12.15 & 8.31 & 15.45 & 2.22 \\
\hline 8.02 & 3.78 & 1.7 & 2243.67 & 1696.25 & 2026.44 & 23 & 5 & 6 & 21.74 & 0.00 & 16.67 & 23.58 & 0 & 17.25 & 1.35 & 24.54 & 32.22 & 22 & 29.35 & 14.88 \\
\hline 6.96 & 0.56 & 6.97 & 1854.72 & 1604.73 & 2330.81 & 10 & 8 & 20 & 20.00 & 12.50 & 20.00 & 21.95 & 15.12 & 18.94 & 14.9 & 22.68 & 17.27 & 6.83 & 35.9 & 1.03 \\
\hline 7.01 & 3.02 & 5.51 & 1936.98 & 2234.28 & 2407.91 & 25 & 24 & 10 & 16.00 & 16.67 & 20.00 & 28.33 & 18.29 & 23.19 & 5.25 & 22.4 & 0 & 9.88 & 10.32 & 7.53 \\
\hline 4.51 & 3.76 & 10.56 & 2572.29 & 1902.54 & 1907.05 & 6 & 15 & 9 & 16.67 & 6.67 & 33.33 & 22.03 & 10.54 & 34 & 24.03 & 14.9 & 12.77 & 9.62 & 22.03 & 3.63 \\
\hline 2.46 & 1.46 & 4.62 & 1704.71 & 1608.22 & 2393.15 & 21 & 10 & 30 & 28.57 & 20.00 & 23.33 & 34.26 & 29.98 & 20.05 & 11.58 & 13.92 & 13.02 & 19.22 & 7.22 & 24.97 \\
\hline 3.71 & 4.98 & 6.31 & 1965.25 & 1994.96 & 1623.36 & 8 & 22 & 22 & 12.50 & 13.64 & 9.09 & 9.35 & 14.76 & 5.27 & 13.52 & 11.15 & 6.68 & 0.62 & 18.73 & 7.67 \\
\hline 16.11 & 3.96 & 2.26 & 2274.03 & 1956.94 & 2101.34 & 17 & 11 & 19 & 17.65 & 9.09 & 15.79 & 29.42 & 10 & 15.74 & 0.4 & 33.27 & 19.03 & 1.05 & 7.52 & 5.53 \\
\hline 4.64 & 3.96 & 12.06 & 1529.13 & 1588.10 & 2308.45 & 10 & 18 & 27 & 10.00 & 11.11 & 18.52 & 4.54 & 11.85 & 19.57 & 5 & 21.32 & 18.25 & 7.03 & 15.78 & 1.7 \\
\hline 5.6 & 6.53 & 13.08 & 2111.62 & 2502.09 & 2453.90 & 20 & 12 & 17 & 25.00 & 8.33 & 23.53 & 26 & 7.42 & 22.46 & 35.6 & 13.92 & 3.95 & 12.27 & 18.25 & 21.28 \\
\hline 10.18 & 3.51 & 2.25 & 2385.22 & 1873.10 & 1532.85 & 18 & 19 & 8 & 16.67 & 15.79 & 25.00 & 17.55 & 14.11 & 26.57 & 23.95 & 12.72 & 9.65 & 8.64 & 20.33 & 3.08 \\
\hline$d f$ & $F$ & $P$ & $d f$ & $F$ & $P$ & $d f$ & F & $P$ & $d f$ & $F$ & $P$ & $d f$ & $F$ & $P$ & $d f$ & $F$ & $P$ & $d f$ & $F$ & P \\
\hline 2,33 & 4.183 & 0.024 & 2,33 & 1.875 & 0.169 & 2,33 & 0.104 & 0.901 & 2,33 & 9.108 & 0.001 & 2,33 & 3.465 & 0.043 & 2,33 & 3.422 & 0.045 & 2,33 & 5.78 & 0.007 \\
\hline
\end{tabular}

The mice in groups of Con, CRS and Bif+CRS were given with distilled water $(10 \mathrm{~mL} / \mathrm{kg})$, distilled water $(10 \mathrm{~mL} / \mathrm{kg})$, B. adolescentis $\left(0.25 \times 10^{9} \mathrm{CFU} / \mathrm{kg}\right)$ respectively, by gavage for 21 days. $\mathrm{N}=12 \mathrm{per}$ group. 
TABLE 3 | B. adolescentis reversed the imbalance of the intestinal microflora induced by CRS at the phylum level.

\begin{tabular}{|c|c|c|c|c|c|c|c|c|c|c|c|}
\hline \multicolumn{3}{|c|}{ A. Shannon index on Phylum level } & \multicolumn{3}{|c|}{ B. PCA on Phylum level } & \multicolumn{3}{|c|}{$\begin{array}{l}\text { D. Proportion of sequences on } \\
\text { Phylum level: Firmicutes }\end{array}$} & \multicolumn{3}{|c|}{$\begin{array}{l}\text { E. Proportion of sequences on } \\
\text { Phylum level: Bacteroidetes }\end{array}$} \\
\hline Con & CRS & $\mathrm{Bif}+\mathrm{CRS}$ & & PC1 & PC2 & Con & CRS & Bif+CRS & Con & CRS & $\mathrm{Bif}+\mathrm{CRS}$ \\
\hline 0.618248 & 0.804381 & 0.538529 & Con & 1.4023 & -0.1719 & 0.7599 & 0.4212 & 0.8048 & 0.2271 & 0.5547 & 0.186 \\
\hline 0.490792 & 0.785661 & 0.652056 & & 1.4472 & 0.1895 & 0.8335 & 0.646 & 0.6492 & 0.1586 & 0.3226 & 0.3261 \\
\hline 0.639374 & 0.737641 & 0.754216 & CRS & $\begin{array}{c}0.7645 \\
-1.253\end{array}$ & $\begin{array}{r}2.1739 \\
-1.4395\end{array}$ & 0.7751 & 0.6067 & 0.7693 & 0.1977 & 0.3805 & 0.2002 \\
\hline$d f$ & $F$ & $P$ & & -3.2233 & 1.7086 & $d f$ & F & $P$ & $d f$ & $F$ & $P$ \\
\hline 2,6 & 4.5 & 0.064 & $\mathrm{Bif}+\mathrm{CRS}$ & $\begin{array}{r}-0.8385 \\
1.5016 \\
-0.1986 \\
0.3979 \\
0.53264, p\end{array}$ & $\begin{array}{c}-2.0185 \\
-0.047 \\
-0.9116 \\
0.5164 \\
.108\end{array}$ & 2,6 & 5.946 & 0.038 & 2,6 & 5.9 & 0.038 \\
\hline
\end{tabular}

The mice in groups of Con, CRS and Bif+CRS were given with distilled water $(10 \mathrm{~mL} / \mathrm{kg})$, distilled water $(10 \mathrm{~mL} / \mathrm{kg})$, B. adolescentis $(0.25 \times 109$ CFU/kg) respectively, by gavage for 21 days. $N=3$ per group.

TABLE 4 | B. adolescentis reversed the imbalance of the intestinal microflora induced by CRS at the genus level.

A. Shannon index on Genus level

\begin{tabular}{ccc}
\hline Con & CRS & Bif+CRS \\
\hline 1.29678 & 2.136918 & 1.103383 \\
1.106301 & 1.925281 & 1.781085 \\
1.511226 & 1.984399 & 1.145668
\end{tabular}

$d f$
2,6

$$
\begin{gathered}
F \\
7.294
\end{gathered}
$$

B. PCA on Genus level

\begin{tabular}{ccc}
\hline & NMDS1 & NMDS2 \\
\hline Con & -4.3868 & -1.0162 \\
& -3.218 & -1.3881 \\
CRS & -4.0307 & -0.46 \\
& -1.8479 & 9.6013 \\
& 7.3032 & -0.9993 \\
Bif+CRS & -3.495 & 2.9059 \\
& -3.6345 & -0.6355 \\
& -2.0275 & -2.618 \\
& 3.3472 & -5.3902
\end{tabular}

D. Proportion of sequences on

Genus level: Lactobacillus

Con CRS

$\begin{array}{lll}0.684 & 0.261 & 0.7448\end{array}$

$\begin{array}{lll}0.7375 & 0.4001 & 0.5294 \\ 0.6449 & 0.3768 & 0.5958\end{array}$

$\begin{array}{lll}0.6449 & 0.3768 & 0.5958\end{array}$

$\begin{array}{ccc}d f & F & P \\ 2,6 & 14.997 & 0.005\end{array}$

E. Proportion of sequences on Genus level:

Bacteroides

$\begin{array}{ccc}\text { Con } & \text { CRS } & \text { Bif+CRS } \\ 0.0057 & 0.0618 & 0.0125 \\ 0.0065 & 0.0188 & 0.0016 \\ 0.0131 & 0.0598 & 0.0006\end{array}$

$P$

$\begin{array}{ccc}d f & F & P \\ 2,6 & 7.488 & 0.023\end{array}$

$R^{2}=0.54811, p=0.008$

The mice in groups of Con, CRS and Bif+CRS were given with distilled water $(10 \mathrm{~mL} / \mathrm{kg})$, distilled water $(10 \mathrm{~mL} / \mathrm{kg})$, B. adolescentis $(0.25 \times 109 \mathrm{CFU} / \mathrm{kg})$ respectively, by gavage for 21 days. $N=3$ per group. 
TABLE 5 | Changes in the protein expression of BDNF, IL-1 $\beta$, TNF- $\alpha, p-N F-k B$ p65 and lba1 in the hippocampus induced by pretreatment with $B$. adolescentis.

\begin{tabular}{|c|c|c|c|c|c|}
\hline & \multicolumn{5}{|c|}{$\begin{array}{l}\text { B. Western blotting analysis for BDNF, IL-1 } \beta \text {, TNF- } \alpha \text {, } \\
\text { p-NF-к B p65 and Iba1 expression }\end{array}$} \\
\hline & BDNF & IL-1 $\beta$ & TNF- $\alpha$ & $\begin{array}{l}\text { p-NF-кB p65/ } \\
\text { NF-кB p65 }\end{array}$ & Iba1 \\
\hline \multirow[t]{4}{*}{ Con } & 1.0723 & 0.9218 & 0.9743 & 0.9441 & 1.1421 \\
\hline & 1.0099 & 1.1345 & 0.8306 & 0.8215 & 0.7453 \\
\hline & 1.0872 & 0.8812 & 1.0628 & 1.1499 & 1.1128 \\
\hline & 0.8307 & 1.0634 & 1.1325 & 1.0852 & 1.0011 \\
\hline \multirow[t]{4}{*}{ CRS } & 0.4894 & 1.1463 & 1.9127 & 1.1227 & 1.1859 \\
\hline & 0.6007 & 1.3988 & 1.7253 & 1.2378 & 1.1808 \\
\hline & 0.6971 & 1.3309 & 1.3475 & 1.4009 & 1.3169 \\
\hline & 0.5803 & 1.3691 & 1.5323 & 1.4565 & 1.5296 \\
\hline \multirow[t]{4}{*}{$\mathrm{Bif}+\mathrm{CRS}$} & 1.5287 & 0.6976 & 1.1223 & 0.9601 & 0.8247 \\
\hline & 1.1179 & 0.9694 & 1.3875 & 0.8072 & 1.0179 \\
\hline & 1.1195 & 1.0616 & 1.1956 & 0.9221 & 0.9956 \\
\hline & 0.6419 & 0.9869 & 1.1328 & 1.0082 & 0.8336 \\
\hline$d f$ & 2,9 & 2,9 & 2,9 & 2,9 & 2,9 \\
\hline$F$ & 5.731 & 9.477 & 13.469 & 9.3 & 7.066 \\
\hline$P$ & 0.025 & 0.006 & 0.002 & 0.006 & 0.014 \\
\hline
\end{tabular}

The mice in groups of Con, CRS and Bif+CRS were given with distilled water $(10 \mathrm{~mL} / \mathrm{kg})$, distilled water $(10 \mathrm{~mL} / \mathrm{kg})$, B. adolescentis $(0.25 \times 109 \mathrm{CFU} / \mathrm{kg})$ respectively, by gavage for 21 days. $N=4$ per group.

The decrease in Lactobacillus abundance $(p<0.01)$ in the CRS group was increased $(p<0.01)$ by $B$. adolescentis. Furthermore, the enhanced abundance of Bacteroides $(p<0.05)$ in the CRS group was also reversed $(p<0.05)$ by $B$. adolescentis (Table 4). The $16 \mathrm{~S}$ rRNA sequencing datasets for this study were deposited at NCBI and are accessible at https://www.ncbi.nlm.nih.gov/sra/PRJNA498761.

\section{B. adolescentis Increased BDNF Expression and Reduced the Expression of Inflammatory Cytokines in the Hippocampus of CRS Mice}

To investigate the relationship between the anti-inflammatory effects and the anxiolytic/antidepressant effects of B. adolescentis and to verify the effects of the inflammatory conditions that are induced by chronic stress, we evaluated protein expression in the hippocampus, which is related to inflammation and chronic stress (Sathyanesan et al., 2017). Chronic stress can trigger both anxiety- and depression-like behaviors as well as reduce BDNF levels (Berry et al., 2012) and additionally, cytokines can attenuate the BDNF level in depression ( $\mathrm{Yu}$ and Chen, 2011). There was a significant difference in BDNF expression $\left(F_{(2,9)}=5.731, p=0.025\right.$, Figure 5B). It is striking that the decreased BDNF expression $(p<0.05)$ in the CRS treated with $B$. adolescentis showed the most drastic increase $(p<0.05)$. Western blotting analysis also showed that the protein levels of IL-1 $\beta\left(F_{(2,9)}=9.477, p=0.006\right.$, Figure $\left.5 \mathrm{C}\right)$, TNF- $\alpha\left(F_{(2,9)}=13.469, p=0.002\right.$, Figure 5D), p-NF-кB p65 $\left(F_{(2,9)}=9.3, p=0.006\right.$, Figure 5E) and Ibal $\left(F_{(2,9)}=7.066\right.$, $p=0.014$, Figure 5F) in the hippocampus were significantly different. The increases $(p<0.01, p<0.01, p<0.05, p<0.05)$ were clearly suppressed ( $p<0.01, p<0.01, p<0.01, p<0.01$ ) in the $B$. adolescentis-treated mice compared with the CRS mice (Table 5). To further explore the correlation between anxiety/depression and inflammation, the protein expression of BDNF, IL- $1 \beta$, TNF- $\alpha$ and Iba 1 were examined in the CA1 region (Berkiks et al., 2018) of the hippocampus, as shown in Figure 6E. The protein expression of $\operatorname{BDNF}\left(F_{(2,6)}=8.868, p=0.016\right.$, Figure 6A), IL-1 $\beta\left(F_{(2,6)}=15.471, p=0.004\right.$, Figure 6B), TNF$\alpha\left(F_{(2,6)}=143.837, p=0\right.$, Figure 6C) and Iba1 $\left(F_{(2,6)}=15.24\right.$, $p=0.004$, Figure 6D) was verified by immunofluorescence (Figure 6F). The integrated density results showed that decreased BDNF expression $(p<0.01)$ was increased by $B$. adolescentis $(p<0.05)$, and the enhanced expression of IL-1 $\beta(p<0.01)$, TNF- $\alpha(p<0.01)$ and Ibal $(p<0.01)$ was reduced $(p<0.01$, $p<0.01, p<0.01$ ) by $B$. adolescentis (Table 6). The results imply that $B$. adolescentis increases BDNF expression under CRS conditions related to its anti-inflammatory effects in the hippocampus.

\section{DISCUSSION}

Here, we present novel evidence that $B$. adolescentis prevents the development of anxiety- and depression-like behaviors caused by CRS and that the effects of $B$. adolescentis are related to reducing inflammatory cytokines and rebalancing the gut microbiota.

The gut immune system consists of $70 \%-80 \%$ of the body's immune cells (Furness et al., 1999). Injury to the gastrointestinal tract, which is induced by CRS and related to the alteration of intestinal flora, triggers the discrimination of pathogenic and commensal microorganisms by the gut immune system and an immune response to the pathogen (Artis, 2008). The immune system is an indispensable part of central nervous system activity, including anxiety (Bercik et al., 2010) and depression (Hayley, 2011; Park et al., 2011). Additionally, intestinal flora exert substantial impacts on brain function through immune pathways by inducing the release of inflammatory cytokines into the circulatory system and then into the brain through the transport system of the blood brain barrier to directly influence brain activity and function (Pfau et al., 2018). Moreover, alterations in brain activity and function contribute to behavioral changes (Foster, 2016).

Depressed patients exhibit dysbiosis of gut bacteria or alterations in enteric microorganisms (Aizawa et al., 2016; Zheng et al., 2016; Dinan and Cryan, 2017; Fung et al., 2017). Chronic stress and depression were found to increase both the diversity and richness of gut bacterial populations (Naseribafrouei et al., 2014; Jiang et al., 2015; Li et al., 2018), but this result is in contrast to others (Kelly et al., 2016; Bharwani et al., 2017). In our study, an increase in gut bacterial $\alpha$-diversity (Shannon index) was found in the CRS group, indicating that it is possible that CRS triggers an increase in the diversity of microbiota similar to dysbiosis induced by depression in patients.

Furthermore, Lactobacillus was reduced in the CRS group compared with the control group. Women who receive Lactobacillus rhamnosus HN001 have significantly lower depression and anxiety scores in the postpartum period, and appropriate intervention with Lactobacillus is beneficial for depressive patients (Slykerman et al., 2017). Our data reinforce the essential link between anxiety/depression and the abundance of Lactobacillus. The data showed an increase in 
TABLE 6 | Changes in the protein expression of BDNF, IL-1 $\beta$, TNF- $\alpha$ and Iba1 in the CA1 region of the hippocampus induced by pretreatment with B. adolescentis.

\begin{tabular}{|c|c|c|c|c|c|c|c|c|c|c|c|c|}
\hline & Con & & & CRS & & & Bif + CRS & & & $d f$ & $F$ & $P$ \\
\hline BDNF & 14,751 & 10,982 & 15,237 & 8,019 & 9,727 & 8,762 & 13,296 & 14,505 & 12,274 & 2,6 & 8.868 & 0.016 \\
\hline IL-1 $\beta$ & 3,433 & 4,576 & 5,334 & 8,892 & 7,734 & 9,565 & 4,654 & 5,672 & 6,708 & 2,6 & 15.471 & 0.004 \\
\hline TNF- $\alpha$ & 2,829 & 4,075 & 3,323 & 15,288 & 14,169 & 16,283 & 7,956 & 8,932 & 7,249 & 2,6 & 143.837 & 0 \\
\hline lba1 & 6,533 & 7,142 & 5,706 & 10,026 & 8,717 & 10,696 & 5,719 & 6,477 & 7,329 & 2,6 & 15.24 & 0.004 \\
\hline
\end{tabular}

The mice in groups of Con, CRS and Bif+CRS were given with distilled water (10 mL/kg), distilled water (10 mL/kg), B. adolescentis (0.25 × 109 CFU/kg), respectively, by gavage for 21 days. $N=3$ per group.

Lactobacillus in the CRS plus B. adolescentis group, verifying that the Lactobacillus increase was probably a major factor in preventing anxiety and depression. Consistent with the previous study, this study presumes that highly diverse bacterial communities, which are likely included in the pathogenesis of stress-induced behavioral deficits, are related to decreased Lactobacillus abundance (Li et al., 2018). The recovery of intestinal Lactobacillus levels is effective in improving behavioral deficits. Host kynurenine metabolism may be suppressed by reactive oxygen species derived by Lactobacillus via inhibiting the metabolizing enzyme IDO1 in the intestine (Marin et al., 2017).

It has been reported that $80 \%$ of patients with depression have a high proportion of Bacteroides in the fecal microbiota (Liu et al., 2016). As our study showed, the increased Bacteroides proportion in the CRS group was reversed by pretreatment with $B$. adolescentis, and at the same time, the decreased Firmicutes proportion in the CRS group was reversed by pretreatment with $B$. adolescentis. However, another controversial report showed that (R)-ketamine significantly increases the levels of Bacteroidales in susceptible mice after chronic social defeat stress (CSDS; Qu et al., 2017). The difference between the trends of Bacteroidales and Bacteroides may result from the different models, drugs and drug doses. The antidepressant effects of (R)ketamine in a CSDS model may be regulated by the rebalancing of the intestinal microbiota to some extent, and (R)-ketamine can reduce the level of Butyricimonas in susceptible mice (Yang et al., 2017b). Moreover, Clostridium butyricum, a probiotic, augments 5-HT and BDNF expression, and its antidepressant effects in mice exposed to chronic unpredictable mild stress are partly due to the stimulation of intestinal glucagon-like peptide-1 secretion (Sun et al., 2018). The distinct appearance of Bifidobacterium is discovered in unsusceptible (resilient) mice and additionally, the administration of Bifidobacterium may confer resilience against CSDS (Yang et al., 2017a). Together, these findings show that the antidepressant mechanisms of Bifidobacterium related to the intestinal flora are complicated and require further investigation.

Gut microbiota can influence peripheral inflammation or CNS processes and subsequent behavioral responses to stress through cytokine-mediated immune signaling pathways, such as by increasing TNF- $\alpha$ (Ren et al., 2018), IL-1 $\beta$ (Grenham et al., 2011), and NF- $\mathrm{B}$ (Wang et al., 2016), which is consistent with our data. Gut microbiota analysis shows that an anti-mouse IL-6 receptor antibody significantly improves the decreased Firmicutes/Bacteroidetes ratio in susceptible mice in a CSDS model (Zhang et al., 2017). It is possible that the increased Firmicutes and decreased Bacteroidetes levels induced by $B$. adolescentis are related to blockade of the IL- 6 receptor. The gene expression of IL-1 $\beta$ in bone marrow-derived macrophage cells is increased after treatment with an isolate of Bacteroides fragilis (Deng et al., 2016). The bacterial flora of neonatal necrotizing enterocolitis patients contain significantly higher amounts of Bacteroides, which is accompanied by an enhancement of TNF- $\alpha$ (Hui et al., 2017), and Bacteroides vulgatus induces NF- $\mathrm{B}$ activation and pro-inflammatory gene expression in intestinal epithelial cells (Haller et al., 2003). These studies show that Bacteroides is positively correlated with inflammatory factors, including IL- $1 \beta$, TNF- $\alpha$, and NF$\kappa \mathrm{B}$. Additionally, a study demonstrated that the anxiolytic effect of $B$. adolescentis IM38 in mice may occur via reducing the blood IL-6 and TNF- $\alpha$ levels (Jang et al., 2018). Our data also showed an increase in Bacteroides and inflammatory cytokines, including IL- $1 \beta$, TNF- $\alpha$ and NF- $\kappa$ B, in the CRS group, and the downregulation of these cytokines after pretreatment with $B$. adolescentis, confirming that a decreased Bacteroides level may be a vital element in the anti-inflammatory effects of $B$. adolescentis.

Lactobacillus brevis 23017 relieves colon toxicity by modulating oxidative stress and inflammation through NF$\kappa \mathrm{B}$ signaling cascades (Jiang et al., 2018). Additionally, our data demonstrate a reduction in Lactobacillus in the CRS group and the upregulation of Lactobacillus after pretreatment with $B$. adolescentis, verifying that an increase in Lactobacillus may be another key factor in the anti-inflammatory actions of $B$. adolescentis.

Microglia, which participate in synaptic pruning, promoting tissue repair, and recruiting peripheral leukocytes to sites of inflammation, have been observed in brain regions such as the hippocampus, amygdala, and prefrontal cortex (Wohleb, 2016; Ménard et al., 2017). B. adolescentis NK98 can inhibit the infiltration of Ibal into the hippocampus caused by the acute immobilization stress (Jang et al., 2019). In our study, the $B$. adolescentis-pretreated group showed reduced Ibal levels following CRS, which is in agreement with previously published studies that have highlighted the potential therapeutic efficacy of targeting central inflammatory processes, particularly those mediated by microglia, in depression (Alcocer-Gómez et al., 2016).

This study has a few limitations. First, in the preliminary efficacy screening experiment, $B$. adolescentis showed anxiolytic and antidepressant effects, then the mice were divided into a control group and a $B$. adolescentis-treated group. In our subsequent experiment, to study the anxiolytic and antidepressant mechanisms of $B$. adolescentis, we established a 
B. adolescentis treatment plus CRS group, but we did not use a B. adolescentis-treated group as a control. Second, our current analyses of the gut microbiota and the brain were obtained from three or four samples per group; therefore, a large sample size may be needed in future studies to improve our understanding of the mechanisms underlying the relationship between the gut microbiota and inflammation. Third, the current study is correlational in nature, so no conclusions can be drawn about whether the inflammatory effects are the mechanism for the treatment effect on behavior. It could equally be the case that there is some other mechanism and the inflammatory findings are merely tangential.

\section{CONCLUSION}

In conclusion, we found that $B$. adolescentis increases the sequence proportion of Lactobacillus and reduces the sequence proportion of Bacteroides in feces. Moreover, B. adolescentis decreases IL- $1 \beta$, TNF- $\alpha, \mathrm{NF}-\kappa \mathrm{B}$, and Iba1 protein expression and increases BDNF protein expression in the hippocampus of CRS mice. B. adolescentis has anxiolytic and antidepressant effects on behavioral performance in mice exposed to CRS. Thus, we conclude that the anxiolytic and antidepressant effects of $B$. adolescentis are related to reducing inflammatory cytokines and rebalancing the gut microbiota. Our data will contribute to the understanding of anti-inflammatory effects and the rebalancing of the gut microbiota as possible essential experimental therapeutic strategies for anxiety and depression.

\section{REFERENCES}

Aizawa, E., Tsuji, H., Asahara, T., Takahashi, T., Teraishi, T., Yoshida, S., et al. (2016). Possible association of Bifidobacterium and Lactobacillus in the gut microbiota of patients with major depressive disorder. J. Affect. Disord. 202, 254-257. doi: 10.1016/j.jad.2016.05.038

Alcocer-Gómez, E., Ulecia-Morón, C., Marín-Aguilar, F., Rybkina, T., CasasBarquero, N., Ruiz-Cabello, J., et al. (2016). Stress-induced depressive behaviors require a functional NLRP3 inflammasome. Mol. Neurobiol. 53, 4874-4882. doi: $10.1007 /$ s12035-015-9408-7

Artis, D. (2008). Epithelial-cell recognition of commensal bacteria and maintenance of immune homeostasis in the gut. Nat. Rev. Immunol. 8, 411-420. doi: 10.1038/nri2316

Bercik, P., Verdu, E. F., Foster, J. A., Macri, J., Potter, M., Huang, X., et al. (2010). Chronic gastrointestinal inflammation induces anxiety-like behavior and alters central nervous system biochemistry in mice. Gastroenterology 139, 2102.e1-2112.e1. doi: 10.1053/j.gastro.2010. 06.063

Berkiks, I., Boulbaroud, S., Garcia-Segura, L. M., Mesfioui, A., Ouichou, A., Mouden, S., et al. (2018). Thymelaea lythroides extract attenuates microglial activation and depressive-like behavior in LPS-induced inflammation in adult male rats. Biomed. Pharmacother. 99, 655-663. doi: 10.1016/j.biopha.2018. 01.125

Berry, A., Bellisario, V., Capoccia, S., Tirassa, P., Calza, A., Alleva, E., et al. (2012). Social deprivation stress is a triggering factor for the emergence of anxiety- and depression-like behaviours and leads to reduced brain BDNF levels in C57BL/6J mice. Psychoneuroendocrinology 37, 762-772. doi: 10.1016/j. psyneuen.2011.09.007

Bharwani, A., Mian, M. F., Surette, M. G., Bienenstock, J., and Forsythe, P. (2017). Oral treatment with Lactobacillus rhamnosus attenuates behavioural

\section{ETHICS STATEMENT}

Male ICR mice were purchased from Kunming Medical University. The procedures were approved by the Institutional Animal Care and Use Committee of Kunming Medical University, and were performed in accordance with the Guide for the Care and Use of Laboratory Animals.

\section{AUTHOR CONTRIBUTIONS}

YG and J-PX: conceptualization. KD, X-MH, QW and J-JL: data curation. XL, YY, QX and JX: formal analysis. YG, YY and QW: funding acquisition. H-RL: methodology and writing-review and editing. YG: writing-original draft.

\section{FUNDING}

This work was supported by the National Natural Science Foundation of China (31760297; YY), Applied Basic Research Foundation of Yunnan Province (2017FE467-160; YG) and Yunnan Provincial Department of Education Foundation (601160911; QW). This work was supported by the key project of Applied Bascic Research Foundation of Yunnan Province (Study on the antidepressant active components and mechanism of rosemary), and the cultivation object of Yunnan innovation team (Kunming Medical University innovation team for the discovery and utilization of the active ingredients of toxic medicinal plants).

deficits and immune changes in chronic social stress. BMC Med. 15:7. doi: 10.1186/s12916-016-0771-7

de Pablos, R. M., Herrera, A. J., Espinosa-Oliva, A. M., Sarmiento, M., Muñoz, M. F., Machado, A., et al. (2014). Chronic stress enhances microglia activation and exacerbates death of nigral dopaminergic neurons under conditions of inflammation. J. Neuroinflammation 11:34. doi: 10.1186/17422094-11-34

Deng, H., Li, Z., Tan, Y., Guo, Z., Liu, Y., Wang, Y., et al. (2016). A novel strain of Bacteroides fragilis enhances phagocytosis and polarises M1 macrophages. Sci. Rep. 6:29401. doi: 10.1038/srep29401

Desbonnet, L., Garrett, L., Clarke, G., Bienenstock, J., and Dinan, T. G. (2008) The probiotic Bifidobacteria infantis: an assessment of potential antidepressant properties in the rat. J. Psychiatr. Res. 43, 164-174. doi: 10.1016/j.jpsychires. 2008.03.009

Dinan, T. G., and Cryan, J. F. (2017). Microbes, immunity, and behavior: psychoneuroimmunology meets the microbiome. Neuropsychopharmacology 42, 178-192. doi: 10.1038/npp.2016.103

Evrensel, A., and Ceylan, M. E. (2015). The gut-brain axis: the missing link in depression. Clin. Psychopharmacol. Neurosci. 13, 239-244. doi: 10.9758/cpn. 2015.13.3.239

Fang, M., Yuan, Y., Rangarajan, P., Lu, J., Wu, Y., Wang, H., et al. (2015). Scutellarin regulates microglia-mediated TNC1 astrocytic reaction and astrogliosis in cerebral ischemia in the adult rats. BMC Neurosci. 16:84. doi: 10.1186/s12868-015-0219-6

Farooq, R. K., Isingrini, E., Tanti, A., Le Guisquet, A. M., Arlicot, N., Minier, F., et al. (2012). Is unpredictable chronic mild stress (UCMS) a reliable model to study depression-induced neuroinflammation? Behav. Brain Res. 231, 130-137. doi: 10.1016/j.bbr.2012.03.020

Foster, J. A. (2016). Gut microbiome and behavior: focus on neuroimmune interactions. Int. Rev. Neurobiol. 131, 49-65. doi: 10.1016/bs.irn.2016.07.005 
Fung, T. C., Olson, C. A., and Hsiao, E. Y. (2017). Interactions between the microbiota, immune and nervous systems in health and disease. Nat. Neurosci. 20, 145-155. doi: 10.1038/nn.4476

Furness, J. B., Kunze, W. A., and Clerc, N. (1999). Nutrient tasting and signaling mechanisms in the gut. II. The intestine as a sensory organ: neural, endocrine, and immune responses. Am. J. Physiol. 277, G922-G928. doi: 10.1152/ajpgi. 1999.277.5.g922

Grenham, S., Clarke, G., Cryan, J. F., and Dinan, T. G. (2011). Brain-gut-microbe communication in health and disease. Front. Physiol. 2:94. doi: 10.3389/fphys. 2011.00094

Haller, D., Holt, L., Kim, S. C., Schwabe, R. F., Sartor, R. B., and Jobin, C. (2003). Transforming growth factor- $\beta 1$ inhibits non-pathogenic Gram negative bacteria-induced NF- $\kappa$ B recruitment to the interleukin- 6 gene promoter in intestinal epithelial cells through modulation of histone acetylation. J. Biol. Chem. 278, 23851-23860. doi: 10.1074/jbc.M300075200

Hayley, S. (2011). Toward an anti-inflammatory strategy for depression. Front. Behav. Neurosci. 5:19. doi: 10.3389/fnbeh.2011.00019

Hennessy, M. B., Schiml, P. A., Berberich, K., Beasley, N. L., and Deak, T. (2019). Early attachment disruption, inflammation, and vulnerability for depression in rodent and primate models. Front. Behav. Neurosci. 12:314. doi: 10.3389/fnbeh. 2018.00314

Hodes, G. E., Pfau, M. L., Leboeuf, M., Golden, S. A., Christoffel, D. J., Bregman, D., et al. (2014). Individual differences in the peripheral immune system promote resilience versus susceptibility to social stress. Proc. Natl. Acad. Sci. US A 111, 16136-16141. doi: 10.1073/pnas.1415191111

Hui, L., Dai, Y., Guo, Z., Zhang, J., Zheng, F., Bian, X., et al. (2017). Immunoregulation effects of different $\gamma \delta \mathrm{T}$ cells and toll-like receptor signaling pathways in neonatal necrotizing enterocolitis. Medicine 96:e6077. doi: $10.1097 / \mathrm{md} .0000000000006077$

Jang, H. M., Jang, S. E., Han, M. J., and Kim, D. H. (2018). Anxiolytic-like effect of Bifidobacterium adolescentis IM38 in mice with or without immobilisation stress. Stress 9, 123-132. doi: 10.3920/bm2016.0226

Jang, H. M., Lee, K. E., and Kim, D. H. (2019). The preventive and curative effects of lactobacillus reuteri NK33 and Bifidobacterium adolescentis NK98 on immobilization stress-induced anxiety/depression and colitis in mice. Nutrients 11:E819. doi: 10.3390/nu11040819

Jiang, X., Gu, S., Liu, D., Zhao, L., Xia, S., He, X., et al. (2018). Lactobacillus brevis 23017 relieves mercury toxicity in the colon by modulation of oxidative stress and inflammation through the interplay of MAPK and NF- $\kappa \mathrm{B}$ signaling cascades. Front. Microbiol. 9:2425. doi: 10.3389/fmicb.2018.02425

Jiang, H., Ling, Z., Zhang, Y., Mao, H., Ma, Z., Yin, Y., et al. (2015). Altered fecal microbiota composition in patients with major depressive disorder. Brain Behav. Immun. 48, 186-194. doi: 10.1016/j.bbi.2015.03.016

Kelly, J. R., Borre, Y., O’Brien, C., Patterson, E., El Aidy, S., Deane, J., et al. (2016). Transferring the blues: depression-associated gut microbiota induces neurobehavioural changes in the rat. J. Psychiatr. Res. 82, 109-118. doi: 10.1016/j.jpsychires.2016.07.019

Krishnan, R., Cella, D., Leonardi, C., Papp, K., Gottlieb, A. B., Dunn, M., et al. (2007). Effects of etanercept therapy on fatigue and symptoms of depression in subjects treated for moderate to severe plaque psoriasis for up to 96 weeks. $\mathrm{Br}$. J. Dermatol. 157, 1275-1277. doi: 10.1111/j.1365-2133.2007.08205.x

Li, N., Wang, Q., Wang, Y., Sun, A., Lin, Y., Jin, Y., et al. (2018). Oral probiotics ameliorate the behavioral deficits induced by chronic mild stress in mice via the gut microbiota-inflammation axis. Front. Behav. Neurosci. 12:266. doi: $10.3389 /$ fnbeh.2018.00266

Lim, S. M., and Kim, D. H. (2017). Bifidobacterium adolescentis IM38 ameliorates high-fat diet-induced colitis in mice by inhibiting NF- $\kappa \mathrm{B}$ activation and lipopolysaccharide production by gut microbiota. Nutr. Res. 41, 86-96. doi: 10.1016/j.nutres.2017.04.003

Liu, Y., Zhang, L., Wang, X., Wang, Z., Zhang, J., Jiang, R., et al. (2016). Similar fecal microbiota signatures in patients with diarrhea-predominant irritable bowel syndrome and patients with depression. Clin. Gastroenterol. Hepatol. 14, 1602.e5-1611.e5. doi: 10.1016/j.cgh.2016.05.033

Maes, M. (2008). The cytokine hypothesis of depression: inflammation, oxidative \& nitrosative stress (IO\&NS) and leaky gut as new targets for adjunctive treatments in depression. Neuro Endocrinol. Lett. 29, 287-291.

Maes, M., Song, C., and Yirmiya, R. (2012). Targeting IL-1 in depression. Expert Opin. Ther. Targets 16, 1097-1112. doi: 10.1517/14728222.2012.718331
Manning, J., Kulbida, R., Rai, P., Jensen, L., Bouma, J., Singh, S. P., et al. (2014). Amitriptyline is efficacious in ameliorating muscle inflammation and depressive symptoms in the mdx mouse model of Duchenne muscular dystrophy. Exp. Physiol. 99, 1370-1386. doi: 10.1113/expphysiol.2014.079475

Marin, I. A., Goertz, J. E., Ren, T., Rich, S. S., Onengut-Gumuscu, S., Farber, E., et al. (2017). Microbiota alteration is associated with the development of stressinduced despair behavior. Sci. Rep. 7:43859. doi: 10.1038/srep43859

McKeever, A., Agius, M., and Mohr, P. (2017). A review of the epidemiology of major depressive disorder and of its consequences for society and the individual. Psychiatr. Danub. 29, 222-231.

Ménard, C., Pfau, M. L., Hodes, G. E., and Russo, S. J. (2017). Immune and neuroendocrine mechanisms of stress vulnerability and resilience. Neuropsychopharmacology 42, 62-80. doi: 10.1038/npp.2016.90

Messaoudi, M., Lalonde, R., Violle, N., Javelot, H., Desor, D., Nejdi, A., et al. (2011). Assessment of psychotropic-like properties of a probiotic formulation (Lactobacillus helveticus R0052 and Bifidobacterium longum R0175) in rats and human subjects. Br. J. Nutr. 105, 755-764. doi: 10.1017/s0007114510004319

Meyer, C., and Vassar, M. (2018). The fragility of probiotic Bifidobacterium longum NCC3001 use for depression in patients with irritable bowel syndrome. Gastroenterology 154:764. doi: 10.1053/j.gastro.2017.09.055

Naseribafrouei, A., Hestad, K., Avershina, E., Sekelja, M., Linløkken, A., Wilson, R., et al. (2014). Correlation between the human fecal microbiota and depression. Neurogastroenterol. Motil. 26, 1155-1162. doi: 10.1111/nmo.12378

Oglodek, E. A., Just, M. J., Szromek, A. R., and Araszkiewicz, A. (2017). Assessing the serum concentration levels of NT-4/5, GPX-1, TNF- $\alpha$, and 1-arginine as biomediators of depression severity in first depressive episode patients with and without posttraumatic stress disorder. Pharmacol. Rep. 69, 1049-1058. doi: 10.1016/j.pharep.2017.04.013

Park, S. E., Dantzer, R., Kelley, K. W., and McCusker, R. H. (2011). Central administration of insulin-like growth factor-I decreases depressive-like behavior and brain cytokine expression in mice. J. Neuroinflammation 8:12. doi: 10.1186/1742-2094-8-12

Pfau, M. L., Ménard, C., and Russo, S. J. (2018). Inflammatory mediators in mood disorders: therapeutic opportunities. Annu. Rev. Pharmacol. Toxicol. 58, 411-428. doi: 10.1146/annurev-pharmtox-010617-052823

Qu, Y., Yang, C., Ren, Q., Ma, M., Dong, C., and Hashimoto, K. (2017). Comparison of (R)-ketamine and lanicemine on depression-like phenotype and abnormal composition of gut microbiota in a social defeat stress model. Sci. Rep. 7:15725. doi: 10.1038/s41598-017-16060-7

Ravel, J., Gajer, P., Abdo, Z., Schneider, G. M., Koenig, S. S., McCulle, S. L., et al. (2011). Vaginal microbiome of reproductive-age women. Proc. Natl. Acad. Sci. US A 108, 4680-4687. doi: 10.1073/pnas.1002611107

Ren, Y., Geng, Y., Du, Y., Li, W., Lu, Z. M., Xu, H. Y., et al. (2018). Polysaccharide of Hericium erinaceus attenuates colitis in $\mathrm{C} 57 \mathrm{BL} / 6$ mice via regulation of oxidative stress, inflammation-related signaling pathways and modulating the composition of the gut microbiota. J. Nutr. Biochem. 57, 67-76. doi: 10.1016/j. jnutbio.2018.03.005

Riedel, C. U., Foata, F., Philippe, D., Adolfsson, O., Eikmanns, B. J., and Blum, S. (2006). Anti-inflammatory effects of bifidobacteria by inhibition of LPS-induced NF-кB activation. World J. Gastroenterol. 12, 3729-3735. doi: 10.3748/wjg.v12.i23.3729

Sanna, M. D., Ghelardini, C., and Galeotti, N. (2017). Effect of amitriptyline treatment on neurofilament-H protein in an experimental model of depression. Brain Res. Bull. 128, 1-6. doi: 10.1016/j.brainresbull.2016. 11.001

Sathyanesan, M., Haiar, J. M., Watt, M. J., and Newton, S. S. (2017). Restraint stress differentially regulates inflammation and glutamate receptor gene expression in the hippocampus of C57BL/6 and BALB/c mice. Stress 20, 197-204. doi: 10.1080/10253890.2017.1298587

Slykerman, R. F., Hood, F., Wickens, K., Thompson, J. M. D., Barthow, C., Murphy, R., et al. (2017). Effect of lactobacillus rhamnosus HN001 in pregnancy on postpartum symptoms of depression and anxiety: a randomised doubleblind placebo-controlled trial. EBioMedicine 24, 159-165. doi: 10.1016/j.ebiom. 2017.09.013

Sun, J., Wang, F., Hu, X., Yang, C., Xu, H., Yao, Y., et al. (2018). Clostridium butyricum attenuates chronic unpredictable mild stress-induced depressive-like behavior in mice via the gut-brain axis. J. Agric. Food Chem. 66, 8415-8421. doi: 10.1021/acs.jafc.8b02462 
Trivedi, M. H., Greer, T. L., Grannemann, B. D., Chambliss, H. O., and Jordan, A. N. (2006). Exercise as an augmentation strategy for treatment of major depression. J. Psychiatr. Pract. 12, 205-213. doi: 10.1097/00131746200607000-00002

Wang, W., Li, Z., Han, Q., Guo, Y., Zhang, B., and D’Inca, R. (2016). Dietary live yeast and mannan-oligosaccharide supplementation attenuate intestinal inflammation and barrier dysfunction induced by Escherichia coli in broilers. Br. J. Nutr. 116, 1878-1888. doi: 10.1017/s0007114516004116

Wohleb, E. S. (2016). Neuron-microglia interactions in mental health disorders: "for better, and for worse". Front. Immunol. 7:544. doi: 10.3389/fimmu.2016. 00544

Wong, M. L., Inserra, A., Lewis, M. D., Mastronardi, C. A., Leong, L., Choo, J., et al. (2016). Inflammasome signaling affects anxiety- and depressive-like behavior and gut microbiome composition. Mol. Psychiatry 21, 797-805. doi: $10.1038 / \mathrm{mp} .2016 .46$

Yang, C., Fujita, Y., Ren, Q., Ma, M., Dong, C., and Hashimoto, K. (2017a). Bifidobacterium in the gut microbiota confer resilience to chronic social defeat stress in mice. Sci. Rep. 7:45942. doi: 10.1038/srep45942

Yang, C., Qu, Y., Fujita, Y., Ren, Q., Ma, M., Dong, C., et al. (2017b). Possible role of the gut microbiota-brain axis in the antidepressant effects of (R)-ketamine in a social defeat stress model. Transl. Psychiatry 7:1294. doi: 10.1038/s41398017-0031-4

Yang, L. P., Jiang, F. J., Wu, G. S., Deng, K., Wen, M., Zhou, X., et al. (2015). Acute treatment with a novel TRPC4/C5 channel inhibitor produces antidepressant and anxiolytic-like effects in mice. PLoS One 10:e136255. doi: 10.1371/journal.pone.0136255

Yu, H., and Chen, Z. Y. (2011). The role of BDNF in depression on the basis of its location in the neural circuitry. Acta Pharmacol. Sin. 32, 3-11. doi: 10.1038/aps. 2010.184
Yuan, Y., Zha, H., Rangarajan, P., Ling, E. A., and Wu, C. (2014). Antiinflammatory effects of Edaravone and Scutellarin in activated microglia in experimentally induced ischemia injury in rats and in BV-2 microglia. BMC Neurosci. 15:125. doi: 10.1186/s12868-014-0125-3

Zhang, Y., Liu, L., Liu, Y. Z., Shen, X. L., Wu, T. Y., Zhang, T., et al. (2015). NLRP3 inflammasome mediates chronic mild stress-induced depression in mice via neuroinflammation. Int. J. Neuropsychopharmacol. 18:pyv006. doi: 10.1093/ijnp/pyv006

Zhang, J. C., Yao, W., Dong, C., Yang, C., Ren, Q., Ma, M., et al. (2017). Blockade of interleukin-6 receptor in the periphery promotes rapid and sustained antidepressant actions: a possible role of gutmicrobiota-brain axis. Transl. Psychiatry 7:e1138. doi: 10.1038/tp. 2017.112

Zheng, P., Zeng, B., Zhou, C., Liu, M., Fang, Z., Xu, X., et al. (2016). Gut microbiome remodeling induces depressive-like behaviors through a pathway mediated by the host's metabolism. Mol. Psychiatry 21, 786-796. doi: $10.1038 / \mathrm{mp} .2016 .44$

Conflict of Interest Statement: The authors declare that the research was conducted in the absence of any commercial or financial relationships that could be construed as a potential conflict of interest.

Copyright (C) 2019 Guo, Xie, Deng, Li, Yuan, Xuan, Xie, He, Wang, Li and Luo. This is an open-access article distributed under the terms of the Creative Commons Attribution License (CC BY). The use, distribution or reproduction in other forums is permitted, provided the original author(s) and the copyright owner(s) are credited and that the original publication in this journal is cited, in accordance with accepted academic practice. No use, distribution or reproduction is permitted which does not comply with these terms. 